\title{
Caracterização das áreas de lazer de edifícios e condomínios verticais multifamiliares visando à proposição de um índice de lazer
}

\author{
Characterisation of leisure areas in vertical multifamily \\ buildings aimed at proposing a leisure index
}

\section{Marta Cavalcante Alexandre Márcio Toledo}

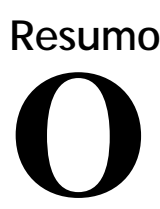

s edifícios verticais multifamiliares apresentam cada vez maior quantidade de ambientes de lazer, possivelmente como resposta às demandas da sociedade de consumo e da violência urbana, cujas novas necessidades exigem mercadorias que se convertem em desejos. O que o mercado imobiliário oferece como ambientes de lazer nesses edifícios? O objetivo é caracterizar a abrangência e a configuração dos ambientes e das áreas de lazer de edifícios verticais multifamiliares, visando à proposição de um índice de lazer. Selecionaram-se 31 empreendimentos de seis construtoras na cidade de Maceió, AL, no período de 2010 a 2015. Separaram-se os empreendimentos em 3 grupamentos, de acordo com a área dos apartamentos, com base no índice de velocidade de venda (IVV); agruparam-se os ambientes de lazer em quatro faixas de usuários; calcularam-se os respectivos índices de lazer. Verificou-se que as áreas de lazer adulto e compartilhado ocorreram em toda a amostra; a maioria dos ambientes de lazer se localiza no pilotis/térreo, alguns na cobertura e no mezanino e poucos no subsolo. Os condomínios de apartamentos menores apresentaram índices de lazer menores que os de apartamentos maiores e edifícios isolados. O índice de lazer proposto mostrou-se adequado para expressar a variada oferta do mercado imobiliário local.

Palavras-chave: Áreas de lazer. Edifícios de apartamentos. Mercado imobiliário. Índice de lazer.

\begin{abstract}
Vertical multifamily buildings now offer an increasing number of leisure environments. That is possibly in response to urban violence and the demands of consumer society, whose new needs demand commodities that turn into desires. What does the real estate market offer as recreational environments in these buildings? The objective of this paper is to characterise the scope and configuration of the environments and leisure areas at vertical multifamily buildings, aiming at proposing a leisure index. A total of 31 developments were selected from six construction companies in the city of Maceió/AL/Brazil, between 2010 and 2015. The projects were divided into 3 groups according to the area of the apartments, based on the Sales Velocity Index; leisure environments were grouped into four user ranges; the respective leisure rates were calculated. The study showed that the adult and shared leisure areas occurred throughout the sample; most of the leisure environments are located on the pilotis/ground floor area, some on the roof and on the mezzanine and a few in the basement. The condominiums with small apartments had lower leisure rates than those with larger apartments and isolated buildings. The proposed leisure index was
\end{abstract}

Recebido em 21/01/19

Aceito em 12/08/19 adequate to express the varied offer of the local real estate market.

1 Marta Cavalcante Maceió - AL - Brasil

${ }^{2}$ Alexandre Márcio Toledo Federal de Alagoas

\section{Introauçao}

CAVALCANTE, M.; TOLEDO, A. M. Caracterização das áreas de lazer de edifícios e condomínios verticais multifamiliares 343 visando à proposição de um índice de lazer. Ambiente Construído, Porto Alegre, v. 20, n. 2, p. 343-365, abr./jun. 2020. 
O mercado imobiliário, por meio de estratégias de publicidade e marketing, vende itens de lazer com status de felicidade, nos novos edifícios de apartamentos, como resposta à sociedade de consumo, diante dos problemas de segurança e da reduzida oferta de lazer nos espaços públicos nas cidades contemporâneas, que levaram à arquitetura do medo.

O mercado imobiliário é o responsável pela efervescência das cidades (BROWN, 2015), enquanto faz surgir edificações em locais desabitados e promove a verticalidade de bairros anteriormente horizontais (LOPES, 2017; SANTOS, 2016). Os agentes do mercado imobiliário desejam criar valor de uso para outros com a intenção de realizar valor de troca para si mesmos. Então buscam, nos projetos de imóveis para venda, flexibilidade, maior rentabilidade, baixo custo de produção, retorno imediato e liquidez. Já o cliente que adquire as unidades habitacionais espera obter conforto, eficiência, imagem e liquidez, mas também deseja que seu imóvel tenha valor de troca em um eventual momento da venda (VARGAS, 2014a).

Villa e Orstein (2009) observaram que, nos últimos anos, algumas empresas de maior porte do setor da construção civil vêm buscando o aumento dos seus índices de produtividade com a finalidade de se tornarem mais competitivas no mercado; porém, os modelos de projetos de edifícios de apartamentos oferecidos por essas empresas se mantêm basicamente os mesmos. Contudo, Vargas (2014c) identifica que, hoje, a ambição comercial do setor imobiliário está voltada para a personalização dos imóveis, apresentando os produtos imobiliários como exclusivos e únicos. A função da personalização, para Baudrillard (2009), não é somente um valor acrescentado, é um valor parasitário. O inessencial é usado para promover o consumo, os quais são tidos como mérito, ligando-se à noção de valor, constituindo a diferença por excesso.

Embora a produção de apartamentos pertença à esfera da construção civil, cujo projeto tem como especialista o arquiteto, a configuração do negócio imobiliário tem envolvido agentes de diversas especialidades com a finalidade de produzir negócios altamente vendáveis e lucrativos. Dessa forma, a cadeia produtiva envolve setores tidos como mais importantes que o dos projetistas do empreendimento, como é o caso da publicidade (VILLA; ORSTEIN, 2009; MONETTI, 2014, ANITELLI; TRAMONTANO, 2011).

O material publicitário, folders de venda dos edifícios, mostra pessoas felizes utilizando as áreas de lazer. São poucos aqueles que apresentam as fachadas do edifício, e menos ainda os que apresentam a planta baixa dos apartamentos. Tem-se a sensação de que se vende a área de lazer e que junto com ela vem um lugar para morar; alguns empreendimentos são verdadeiros clubes, com mais de 20 ambientes de lazer em sua área comum (NASSIF, 2009; SAMPAIO, 2010; DUARTE, 2007; DUARTE; ELALI, 2011). A sociedade de consumo contemporânea busca sempre objetos que estejam na moda, algo que pode ser inessencial (BAUDRILLARD, 2009; BAUMAN, 2008), mas que personalize o seu comprador e o faça único.

Esses edifícios são construídos com o objetivo de venda pelo mercado imobiliário e a publicidade é utilizada como meio de promoção de seus objetos, explorando signos que se relacionam com os interesses do seu público-alvo, dentre esses a felicidade - que pode ser alcançada ao se possuir ambientes de lazer, em condições de segurança. A sociedade de consumo, aquela que consome signos e não objetos (EDWARDS, 2000; FOXALL, 2005; FEATHERSTONE, 1995; CAMPBELL, 2006), está aberta a esse tipo de publicidade e espera ser informada pela mídia sobre a moda do momento que leva à felicidade (VARGAS, 2014b; LIPOVETSKY, 2007).

O lazer é de fundamental importância para o ser humano, não importa a idade nem a classe social. Engloba tanto o descanso quanto a prática de algo prazeroso, quando não há a obrigação de fazê-lo (KOSHAR, 2002; HAWORTH; VEAL, 2004). O lazer é essencial para uma vida saudável; a sua falta leva as pessoas ao cansaço físico e mental, que as prejudica em todas as suas esferas sociais (DUMAZEDIER, 2008; VERMA; LARSON, 2003).

A Declaração dos Direitos Humanos, proclamada pela Assembleia Geral das Nações Unidas, em 1948, estabeleceu no Artigo 24 que cada indivíduo tem “O direito de descanso e lazer, incluindo a limitação razoável de horas de trabalho e férias periódicas remuneradas [...]”. A Convenção das Nações Unidas sobre os Direitos da Criança (1989) estabeleceu "[...] o direito da criança ao descanso e ao lazer, a participar de atividades lúdicas e recreativas apropriadas à idade da criança e a participar livremente da vida cultural e das artes [...]” (EDGINTON, 2009).

Nos últimos 100 anos, a cidade se transformou em um lugar que faz pensar mais no perigo do que na segurança. A vida nas cidades está se convertendo em um estado de natureza caracterizado pela regra do terror e pelo medo onipresente que a acompanha. Surge, então, nesse ambiente “a arquitetura do medo”, como as gated communities - comunidades cercadas por muralhas e vários sistemas de segurança, e alguns equipamentos para inibir a presença dos excluídos (BAUMAN, 2009; ELLIN, 1997). 
Os edifícios verticais multifamiliares com guaritas, muros, câmeras, vigias durante as 24 horas do dia e com várias opções de entretenimento em suas áreas protegidas fazem parte dessa arquitetura do medo, que separa os moradores da cidade dos excluídos que ocupam seus espaços marginais (ELLIN, 1997; SILVA, 2016; KNEBEL, 2017).

Todos que têm melhores condições financeiras adquirem seu apartamento em um condomínio fechado - lugar isolado que fisicamente está dentro da cidade, mas, social e idealmente, está fora dela (BAUMAN, 2009). A violência e a falta de segurança são apontadas como fatores que impedem a livre escolha do lazer das pessoas, contribuindo para que fiquem reféns de suas próprias casas, aumentando o já elevadíssimo número de indivíduos que têm na casa o seu principal “equipamento” de lazer (MARCELLINO et al., 2007).

Pesquisas concluídas no período de 2006 a 2017, realizadas em universidades do Sudeste (NIGRI, 2006; NASSIF, 2009; SAMPAIO, 2010; GAVIÃO, 2012, para as cidades de São Paulo e Rio de Janeiro) e do Sul (MARTYN, 2008; ABREU, 2016; BEZ, 2017, para as cidades de Florianópolis e Porto Alegre) do Brasil, investigaram as áreas de lazer condominiais com focos diversos e utilizaram métodos que incluíram a percepção dos usuários ou a opinião dos outros agentes envolvidos, por meio de avaliação pós-ocupação.

Todas as sete pesquisas utilizaram o estudo de caso como procedimento técnico, envolvendo tanto caso individual como casos múltiplos, com até 13 componentes, em sua maioria para condomínios residenciais verticais e de diversas tipologias e áreas de apartamentos e de diferentes faixas econômicas.

A maioria das pesquisas utilizou como objeto de estudo condomínios residenciais verticais com mais de duas torres, exceto Abreu (2016), que incluiu um edifício residencial multifamiliar vertical isolado. Nenhuma das pesquisas se aprofundou nas áreas dos ambientes de lazer e das áreas de lazer por grupamento etário, na composição da área de lazer total dos condomínios analisados. Apenas Nigri (2006) propôs uma relação da área total de lazer em relação à quantidade de apartamentos; contudo, considerou também no cálculo as áreas comuns de jardins e circulação de pedestres. Além disso, os valores encontrados apresentaram faixas muito amplas, dificultando a comparação entre os casos estudados.

Ao buscar aprofundar essas questões, esse estudo propõe desenvolver um estudo de caso em áreas de lazer de edifícios verticais na cidade de Maceió (09 39' 57" S; 35 44' 07" W), capital do estado de Alagoas, que é a quarta cidade que mais cresce em área urbana no Brasil, com taxa média de crescimento anual de 2,75\%, atrás apenas de Belém (2,79\%), Manaus (2,83\%) e Brasília (2,99\%), segundo relatório da fundação City Mayors centro de estudos dedicado a temas urbanos -, com base em estatísticas de organizações internacionais publicadas de 2006 a 2014. Esse crescimento tanto se deu pela expansão de bairros periféricos, quanto pela intensificação do processo de verticalização, em decorrência da Lei de Abairramento de 2000 (SANTOS, 2016; LOPES, 2017), mesmo sem apresentar crescimento populacional correspondente.

A garantia de locais para atividades de lazer é normatizada pelo Plano Diretor do município de Maceió, em seu artigo $2^{\circ}$, item XII. Relaciona como diretriz nos empreendimentos residenciais a garantia de reserva de áreas livres para lazer. E no artigo 426 define um percentual obrigatório de 10\% da área livre do pavimento pilotis para recreação infantil, preservada do tráfego de veículos (MACEIÓ, 2007). Além disso, estabelece vantagens construtivas à utilização dos pavimentos mezanino e cobertura, para a instalação de áreas de lazer condominiais.

Diante desse contexto, formularam-se as seguintes questões de pesquisa: qual a abrangência e a configuração dos ambientes e das áreas de lazer comuns dos condomínios residenciais e dos edifícios verticais multifamiliares em Maceió? Qual parâmetro poderia expressar a quantidade e a diversidade de ambientes de lazer nesses condomínios e edifícios?

O objetivo desse artigo foi caracterizar a abrangência e a configuração dos ambientes e das áreas de lazer localizados nas áreas comuns dos condomínios e edifícios verticais multifamiliares, na cidade de Maceió, AL, entregues ou em lançamento no período de 2010 até 2015 - que coincide com o crescimento acelerado e a intensificação do processo de verticalização da cidade -, visando à proposição de um índice de lazer para utilização pelos agentes do mercado imobiliário e pesquisadores.

O presente artigo é decorrente de pesquisa realizada no mestrado em arquitetura e urbanismo (COUTINHO, 2016), cujos resultados preliminares foram publicados em evento científico de âmbito nacional (CAVALCANTE; TOLEDO, 2016), com foco nos quatro grupos de lazer propostos. 


\section{Método}

Trata-se de uma pesquisa de natureza aplicada, com abordagem híbrida, tanto qualitativa quanto quantitativa, com tratamento estatístico básico dos dados; quanto aos objetivos é sobretudo uma pesquisa exploratória, visando promover maior familiaridade com o problema de pesquisa, e também descritiva, estabelecendo relações entre as variáveis observadas; utilizou como procedimentos técnicos a pesquisa documental, com base em material publicitário e do acervo técnico das construtoras e corretoras imobiliárias, e o estudo de caso comparado, envolvendo 31 exemplares de condomínios (UR4) e edifícios multifamiliares verticais isolados (UR5), de diferentes tipologias de apartamentos e padrões construtivos.

\section{Definição da amostra}

A definição da amostra foi não probabilística e acidental, visto que dependeu de parâmetros pré-estabelecidos, não havendo distinção entre os elementos que passaram pela primeira triagem. A existência de área de lazer não foi um parâmetro para determinação inicial da amostra; entretanto, foi uma constante em todos os edifícios selecionados pelos portfólios das 6 construtoras pesquisadas (A a F).

Devido à limitação temporal adotada, de 2010 até 2015, e pela qualidade das informações obtidas na coleta dos dados digitais, chegou-se a um total de 31 componentes, dentre eles: 5 condomínios de edifícios verticais multifamiliares, sendo 3 para faixa de renda baixa e 2 para faixa de renda alta, e 26 edifícios verticais multifamiliares isolados, para as faixas de renda média e média-alta; distribuídos em 9 bairros, sendo 3 situados na parte alta (Farol, Antares e Santa Amélia) e 6 na baixada litorânea (Ponta Verde, Cruz das Almas, Guaxuma, Jatiúca, Mangabeiras e Ponta da Terra) da cidade de Maceió, AL (Quadro 1).

\section{Coleta e organização dos dados}

A coleta dos dados ocorreu preliminarmente de forma digital, por meio dos sites das construtoras que possuíam portfólios. Depois disso, realizaram-se visitas de reconhecimento aos empreendimentos já entregues e ocupados por moradores, documentando-se os ambientes e áreas de lazer por meio de registros fotográficos. E, posteriormente, com a aquisição dos projetos dos empreendimentos, em meio digital, por meio de arquivos do programa AutoCad cedidos pelas construtoras.

Dentre os componentes da amostra, havia 11 em fase de lançamento ou em construção e 20 já entregues e ocupados por moradores, no período de levantamento de dados (janeiro a março de 2016). Por essa razão, descartou-se a possibilidade de envolver usuários na pesquisa, já que trabalhos que utilizam avaliação pósocupação consideram pelo menos um ano de ocupação pelos usuários.

Elaboraram-se fichas individuais para cada componente da amostra, contendo: identificação do edifício (nome, letra de A a F, de acordo com a construtora a qual pertence, localização e imagem da fachada), tipologias de apartamentos, áreas das unidades habitacionais, quadro quantitativo e de localização dos ambientes de lazer e plantas baixas dos pavimentos com os ambientes de lazer manipuladas no programa Autocad. Nas fichas de cada empreendimento, a localização dos ambientes de lazer foi observada por meio de cores, em relação ao pavimento (subsolo, pilotis/térreo, mezanino, cobertura e outros).

\section{Grupamento dos condomínios e edifícios}

Utilizou-se como base o índice de velocidade de venda (IVV), disponibilizado pelo Sindicato da Indústria da Construção do Estado de Alagoas (SINDUSCON-AL), no relatório do mês de fevereiro de 2016 (Tabela 1).

Esse índice não é utilizado habitualmente nas pesquisas acadêmicas que tratam de tipologias de apartamentos; porém, é o que o mercado imobiliário local utiliza, sobretudo para o Prêmio Ademi (Associação das Empresas do Mercado Imobiliário de Alagoas), que seleciona os melhores empreendimentos imobiliários de cada ano. O IVV expressa o percentual de vendas em função das ofertas para cada faixa de área considerada das unidades habitacionais. Quanto maior o IVV, melhor o desempenho de vendas.

Dividiram-se os 31 componentes da amostra em 3 grupamentos com subdivisões em grupos, de acordo com as áreas dos apartamentos, garantindo-se ao menos um exemplar para cada uma das faixas de áreas do IVV, com exceção da última (acima de $250 \mathrm{~m}^{2}$ ), em razão de as construtoras selecionadas não operarem com esse nicho de mercado. Os edifícios ou condomínios que possuíam apartamentos com áreas diferentes, que se encaixavam em mais de um grupo, foram denominados de híbridos (Quadro 2). 
Quadro 1 - Componentes da amostra

\begin{tabular}{|c|c|c|c|c|c|c|c|c|}
\hline \multicolumn{2}{|c|}{$\begin{array}{c}\mathbf{N}^{\mathbf{2}} \\
\text { Construt. }\end{array}$} & $\begin{array}{c}\text { Ano } \\
\text { Lanç. }\end{array}$ & $\begin{array}{l}\text { Início } \\
\text { Obras }\end{array}$ & Situação & Edifício/Condomínio & Bairro & $\begin{array}{c}\text { Amb. de } \\
\text { lazer }\end{array}$ & $\begin{array}{c}\text { Tipologia } \\
\text { NNo DORM. }^{\circ} \text { DOR }\end{array}$ \\
\hline 1 & A1 & & & 2010 & Personale & Ponta Verde & 5 & 3 \\
\hline 2 & A2 & & & Entregue & Vitreo & Ponta Verde & 8 & 4 \\
\hline 3 & A3 & & & Entregue & Setai & Cruz das Almas & 6 & 1 e 2 \\
\hline 4 & A4 & 2015 & & & One & Ponta Verde & 8 & 3 e 4 \\
\hline 5 & A5 & 2015 & & & Gran Marine & Guaxuma & 26 & 3 e 4 \\
\hline 6 & A6 & 2015 & & & Hit & Jatiúca & 10 & $3+\mathrm{REV}$ \\
\hline 7 & A7 & 2015 & & & Prime & Mangabeiras & 7 & 3 \\
\hline 8 & A8 & 2015 & & & Life & Jatiúca & 13 & 3 \\
\hline 9 & A9 & & & 2011 & Amalfi & Ponta da Terra & 8 & 3 \\
\hline 10 & A10 & & & Entregue & Atmosfhera & Jatiúca & 6 & 3 \\
\hline 11 & A11 & & & 2010 & Versatile & Jatiúca & 4 & 2 e 3 \\
\hline 12 & A12 & & & Entregue & Vitta & Ponta Verde & 5 & $2+\mathrm{REV}$ \\
\hline 13 & A13 & & & & Double & Ponta Verde & 7 & 3 e 4 \\
\hline 14 & B1 & & 2015 & & Mirante Clube Stratégia & Farol & 20 & 3 \\
\hline 15 & $\mathrm{~B} 2$ & & & Entregue & Dulce Tenório & Farol & 6 & 2 e 3 \\
\hline 16 & B3 & & & Entregue & Dilma Paiva & Farol & 11 & 2 e 3 \\
\hline 17 & $\mathrm{C} 1$ & & & 2013 & Cádiz & Ponta Verde & 3 & 3 \\
\hline 18 & $\mathrm{C} 2$ & 2010 & & 2014 & Mares do Sul & Jatiúca & 8 & 2 e 3 \\
\hline 19 & $\mathrm{D} 1$ & & & 2014 & Res. Alto das Alamedas & Mangabeiras & 29 & 3 \\
\hline 20 & E1 & & & 2015 & Parque Paraíso das Águas & Antares & 7 & 1 e 2 \\
\hline 21 & E2 & & obra & & Parque Pontal das Marés & Antares & 7 & 2 \\
\hline 22 & E3 & & obra & & Mundaú Cond. Clube & Santa Amélia & 6 & 2 \\
\hline 23 & F1 & & & 2010 & Iluminatto & Jatiúca & 3 & $2+\mathrm{REV}$ \\
\hline 24 & $\mathrm{~F} 2$ & & 2015 & & Syrah & Jatiúca & 19 & 3 \\
\hline 25 & F3 & & 2011 & 2014 & Índico & Jatiúca & 3 & 3 \\
\hline 26 & F4 & & 2010 & 2013 & Luna Dorata & Ponta Verde & 8 & 2 e 3 \\
\hline 27 & F5 & & 2012 & 2015 & Sangiovese & Jatiúca & 11 & 1 e 2 \\
\hline 28 & F6 & & 2011 & 2014 & Chardonnay & Ponta Verde & 8 & 3 \\
\hline 29 & F7 & & & 2012 & Spazio Vitalle & Ponta Verde & 4 & 1 e 2 \\
\hline 30 & F8 & 2008 & & 2011 & Classic & Ponta Verde & 11 & 4 \\
\hline 31 & F9 & & 2014 & & Pinot Noir & Ponta Verde & 10 & $1 \mathrm{e} 2$ \\
\hline
\end{tabular}

Nota: Legenda:

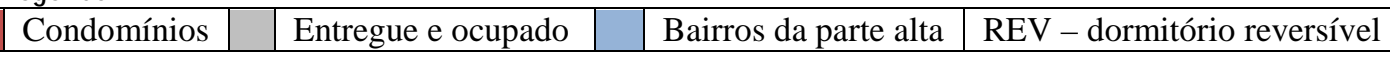

Tabela 1 - Índice de velocidade de venda de fevereiro de 2016

\begin{tabular}{|c|c|c|c|c|c|}
\hline ÁREA $\left(m^{2}\right)$ & OFERTAS & $\%$ & VENDAS & $\%$ & IVV \\
\hline Até 50 & 607 & 25 & 25 & 43 & 4,1 \\
\hline 51 a 70 & 786 & 33 & 15 & 26 & 1,9 \\
\hline 71 a 100 & 418 & 18 & 6 & 10 & 1,4 \\
\hline 101 a 150 & 504 & 21 & 10 & 17 & 2,0 \\
\hline 151 a 200 & 56 & 2 & 2 & 3 & 3,6 \\
\hline 200 а 250 & 9 & 0 & 0 & 0 & 0 \\
\hline Acima de 250 & 5 & 0 & 0 & 0 & 0 \\
\hline Total & 2.385 & 100 & 58 & 100 & - \\
\hline
\end{tabular}

Fonte: Sindicato da Indústria (2016). 
Quadro 2 - Grupamentos e grupos

\begin{tabular}{|c|c|}
\hline GRUPAMENTOS & GRUPOS \\
\hline \multirow{5}{*}{$\begin{array}{l}\text { A } \\
11 \\
8 \text { edifícios } \\
3 \text { condomínios }\end{array}$} & A1 - até $50 \mathrm{~m}^{2}$ \\
\hline & Parque Paraíso das Águas e Parque Pontal das Marés \\
\hline & A2 - Híbridos: até $50 \mathrm{~m}^{2}$ e $51 \mathrm{~m}^{2}$ a $70 \mathrm{~m}^{2}$ \\
\hline & Mundaú Condomínio Clube, Setai, Sangiovese, Spazio Vitalle e Pinot Noir \\
\hline & 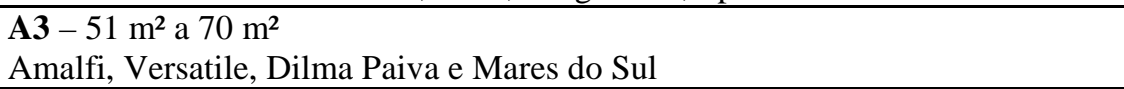 \\
\hline \multirow{4}{*}{$\begin{array}{l}\text { B } \\
9 \\
8 \text { edifícios } \\
1 \text { condomínio }\end{array}$} & $\begin{array}{l}\text { B1 - híbridos: } 51 \mathrm{~m}^{2} \text { a } 70 \mathrm{~m}^{2} \text { e } 71 \mathrm{~m}^{2} \text { a } 100 \mathrm{~m}^{2} \\
\text { Dulce Tenório e Luna Dorata }\end{array}$ \\
\hline & B2 - $71 \mathrm{~m}^{2}$ a $100 \mathrm{~m}^{2}$ \\
\hline & $\begin{array}{l}\text { Life, Vitta, Indico, Personale e lluminatto } \\
\text { B3 - híbridos: } 71 \mathrm{~m}^{2} \text { a } 100 \mathrm{~m}^{2} \text { e } 101 \mathrm{~m}^{2} \text { a } 150 \mathrm{~m}^{2}\end{array}$ \\
\hline & Mirante Clube Stratégia e Residencial Alto das Alamedas \\
\hline \multirow{3}{*}{$\begin{array}{l}\mathbf{C} \\
10 \text { edifícios } \\
1 \text { condomínio }\end{array}$} & $\mathbf{C 1}-101 \mathrm{~m}^{2}$ a $150 \mathrm{~m}^{2}$ \\
\hline & $\begin{array}{l}\text { One, Gran Marine, Hit, Atmosfhera, Cádiz, Prime, Syrah, Chardonnay e } \\
\text { Classic }\end{array}$ \\
\hline & $\begin{array}{l}\mathbf{C} 2-151 \mathrm{~m}^{2} \text { a } 200 \mathrm{~m}^{2} \text { e } 201 \mathrm{~m}^{2} \text { a } 250 \mathrm{~m}^{2} \\
\text { Double e Vitreo }\end{array}$ \\
\hline
\end{tabular}

\section{Definição dos grupos de lazer}

A manipulação dos dados primários obtidos, que apresentou 35 tipos diferentes de ambientes de lazer destinados a determinados grupos de usuários, levou à formação de 4 grupos de lazer (Quadro 3), semelhantes aos adotados por Nigri (2006), substituindo-se “adolescentes” por lazer juvenil e “todos” por lazer compartilhado (CAVALCANTE; TOLEDO, 2016).

Optou-se pelas faixas de usuários em detrimento das cinco dimensões do lazer destacadas por Nigri (2006), que de certa forma apresentam correspondência: espaços de estar e convívio, espaços para as práticas esportivas e espaços de lazer contemplativo com o grupo lazer compartilhado; espaços de lazer infantojuvenil com os grupos lazer infantil e lazer juvenil; espaços de relaxamento com o grupo lazer adulto.

\section{Caracterização das áreas de lazer dos edifícios}

A caracterização das áreas de lazer se deu pela identificação em fichas específicas da ocorrência dos 35 ambientes de lazer (Quadro 4), distribuídos nos 4 grupos de lazer (infantil, juvenil, adulto e compartilhado); descrição da organização e distribuição espacial das zonas de lazer e dos ambientes de lazer, pelos diversos pavimentos (pilotis, térreo, mezanino, cobertura, subsolo e outros) do edifício/condomínio e quantificação das áreas de cada um dos ambientes e grupos de lazer.

Neste artigo, a título de ilustração, apresentam-se as plantas baixas dos casos mais significativos, e as fichas síntese da distribuição dos grupos de lazer nos pisos dos edifícios e condomínios. A totalidade das fichas e plantas baixas dos 31 exemplares encontram-se fartamente detalhadas em Coutinho (2016).

\section{Cálculo do índice de lazer}

O cálculo do índice de lazer resultou da razão entre a área total de lazer - que compreende a soma das áreas dos quatro grupos de lazer - e o número provável de habitantes de cada condomínio ou edifício isolado, estimado em 2 pessoas para cada dormitório do setor íntimo, dos apartamentos de 1 e 2 dormitórios; 5 pessoas para 3 dormitórios e 6 pessoas para 4 dormitórios; incluindo os dormitórios reversíveis, com base na NBR5665/1983 (cálculo de tráfego nos elevadores), desconsiderando empregados domésticos e funcionários do edifício.

Por meio desse novo parâmetro proposto, realizaram-se análises cruzadas internas nos grupos (1, 2 e 3) de cada um dos 3 grupamentos (A, B e C), considerando os tamanhos e as tipologias dos apartamentos. 
Quadro 3 - Grupos de lazer por usuários

\begin{tabular}{|l|l|}
\hline \multicolumn{1}{|c|}{ GRUPO } & \multicolumn{1}{c|}{ USUÁRIOS } \\
\hline $\mathbf{1}$ Lazer infantil & $\begin{array}{l}\text { Crianças pequenas que necessitam da supervisão de adultos. Esse grupo } \\
\text { possui 6 ambientes de lazer: piscina infantil, playground, brinquedoteca, } \\
\text { berçário, minigolfe e xadrez/dama gigante. }\end{array}$ \\
\hline $\mathbf{2}$ & $\begin{array}{l}\text { Crianças maiores e adolescentes que não precisam de supervisão nos } \\
\text { ambientes de lazer. Esse grupo possui 5 ambientes de lazer: sala de estudos, } \\
\text { ateliê de artes, lan house, espaço teen e garage band. }\end{array}$ \\
\hline $\mathbf{3}$ & $\begin{array}{l}\text { Adultos, provavelmente os proprietários das unidades habitacionais. Esse } \\
\text { grupo possui 14 ambientes de lazer: piscina adulto, piscina coberta, piscina } \\
\text { relax, piscina senadinho, sauna, spa zen, espaço "fitness”, ginástica, "home } \\
\text { office”, longe praia, espaço mulher, bar, pista de "cooper” e redário. }\end{array}$ \\
\hline $\begin{array}{l}\mathbf{4} \\
\text { Lazer compartilhado }\end{array}$ & $\begin{array}{l}\text { Crianças, adolescentes e adultos, em conjunto. Esse grupo possui 10 } \\
\text { ambientes de lazer: terraço descoberto, churrasqueira, espaço gourmet, salão } \\
\text { de festas fechado, salão de festas open, praça, salão de jogos, quadra } \\
\text { poliesportiva, quadra de praia e "home cine”. }\end{array}$ \\
\hline
\end{tabular}

\section{Resultados e discussões}

\section{Caracterização das áreas de lazer: grupamento A}

O grupamento A, com 11 empreendimentos divididos em 3 grupos (A1, A2 e A3), apresentou muitas similaridades: os ambientes do lazer infantil e juvenil ocorreram apenas no pavimento pilotis/térreo, com maior frequência para o playground e pouca ocorrência para os ambientes do lazer juvenil. Os ambientes de lazer adulto e compartilhado ocorreram nos pavimentos pilotis/térreo e cobertura, nos edifícios isolados, com maior frequência para os ambientes piscina adulto e espaço fitness, no lazer adulto, e salão de festas ou espaço gourmet e praça, no lazer compartilhado.

O grupo A1 (UH até $50 \mathrm{~m}^{2}$, composto por 2 condomínios, com apartamentos das tipologias de 1 e 2 dormitórios, produzidos pela mesma construtora) apresentou muitas similaridades. Os portfólios de ambos se confundem e mostram ambientes de lazer e blocos de apartamentos semelhantes, com apartamentos também no pavimento térreo, para faixa de renda mais baixa.

Todos os ambientes de lazer ocorrem no pavimento térreo, sem existência do pilotis (Tabela 3). No grupo lazer infantil, a maior ocorrência é o playground e a piscina infantil. Não há ambientes do grupo lazer juvenil. No lazer adulto, a piscina e o espaço fitness. E no lazer compartilhado, o salão de festas e o espaço gourmet, que funciona como bar com churrasqueira (Figura 1).

Os dois condomínios apresentam os ambientes mínimos de lazer observados por Martyn (2008) e Bez (2017), em condomínios de Florianópolis. O grupo de lazer adulto é o que possui maior área construída nos dois condomínios, em torno de 50\% do total da área de lazer (Tabela 2).

Todos os ambientes de lazer nos dois condomínios estão agrupados formando uma única área de lazer próxima às vias de carros e ao lado de um dos blocos de apartamentos. Os ambientes são interligados e não há setorização dos ambientes de lazer por grupo de usuários.

O Cond. Parque Pontal das Marés possui o dobro de área de lazer por morador (0,47 m²/morador), em relação ao Cond. Parque Paraíso das Águas (0,23 m²/morador).

O grupo A2 (UH até $50 \mathrm{~m}^{2}$ e de $51 \mathrm{~m}^{2}$ a $70 \mathrm{~m}^{2}$, com edificações híbridas, composto por 1 condomínio e 4 edifícios isolados, das tipologias de 1 e 2 dormitórios) apresenta áreas de lazer compostas por ambientes de lazer diferenciados, porém organizados de maneira semelhante.

Os ambientes dos grupos lazer infantil e juvenil ocorrem apenas no pavimento térreo. O ambiente infantil de maior ocorrência foi o playground, implantado em local aberto e descoberto em 3 edifícios, e no pilotis em um deles. O grupo lazer juvenil ocorreu apenas em 2 edifícios, com o ambiente de lazer lan house. Os ambientes dos grupos lazer adulto e compartilhado ocorreram nos pavimentos pilotis/térreo e cobertura (Tabela 4), diferentemente do encontrado nos condomínios das quatro cidades pesquisadas: Rio de Janeiro, São Paulo, Florianópolis e Porto Alegre. 
Quadro 4 - Ficha de distribuição dos ambientes de lazer por pavimentos

\begin{tabular}{|c|c|c|c|c|c|c|c|c|c|c|c|c|}
\hline & LAZER & |FANTI| & & & & LA & ERJUV & NIL & & & (0) & \\
\hline $\begin{array}{lc}\begin{array}{l}\text { Piscina } \\
\text { infantil }\end{array} & \text { Play } \\
\text { ground }\end{array}$ & $\begin{array}{l}\text { Binque } \\
\text { doteca }\end{array}$ & $\begin{array}{l}\text { Ber } \\
\text { çário }\end{array}$ & $\begin{array}{l}\text { Mini } \\
\text { golfe }\end{array}$ & $\begin{array}{c}\text { xadrez/ } \\
\text { dama }\end{array}$ & $\begin{array}{l}\text { sala de } \\
\text { estudos }\end{array}$ & $\begin{array}{c}\text { ateliê } \\
\text { de arte }\end{array}$ & $\begin{array}{l}\text { lan } \\
\text { house }\end{array}$ & $\begin{array}{l}\text { espaço } \\
\text { teen }\end{array}$ & $\begin{array}{l}\text { garage } \\
\text { band }\end{array}$ & & AMB & IIES \\
\hline & & & & & LAZER, & DULTO & & & & & & \\
\hline & & LA: & RCOM & PARाIL & ADO & & & & & & & \\
\hline $\begin{array}{ll}\text { Terraço } & \text { Churras } \\
\text { descob. } & \text { queira }\end{array}$ & $\begin{array}{l}\text { Espaço } \\
\text { goumet }\end{array}$ & $\begin{array}{l}\text { Sal. festa } \\
\text { fechado }\end{array}$ & $\begin{array}{l}\text { Sal. festas } \\
\text { open }\end{array}$ & praça & $\begin{array}{l}\text { Salão de } \\
\text { jogos }\end{array}$ & $\begin{array}{l}\text { Polies } \\
\text { portiva }\end{array}$ & $\begin{array}{l}\text { Vôlei de } \\
\text { praia }\end{array}$ & $\begin{array}{l}\text { Home } \\
\text { cine }\end{array}$ & & & & \\
\hline
\end{tabular}

Tabela 2 - Distribuição das áreas de lazer - Grupo A

\begin{tabular}{|c|c|c|c|c|c|c|c|c|c|c|}
\hline \multirow{3}{*}{ Grupo } & \multirow{3}{*}{ Condomínio/Edifício } & \multicolumn{8}{|c|}{ Grupo de Lazer } & \multirow{3}{*}{$\frac{\text { Total }}{\mathrm{m}^{2}}$} \\
\hline & & \multicolumn{2}{|c|}{ Infantil } & \multicolumn{2}{|c|}{ Juvenil } & \multicolumn{2}{|c|}{ Adulto } & \multicolumn{2}{|c|}{ Compartilhado } & \\
\hline & & $\mathbf{m}^{2}$ & $\%$ & $\mathrm{~m}^{2}$ & $\%$ & $\mathrm{~m}^{2}$ & $\%$ & $\mathrm{~m}^{2}$ & $\%$ & \\
\hline \multirow{2}{*}{ A1 } & Cond. P. P. das Águas & 89,54 & 27,34 & 0 & 0 & 160,97 & 49,14 & 77,05 & 23,52 & 327,56 \\
\hline & Cond. P. P. das Marés & 115,5 & 25,57 & 0 & 0 & 229,10 & 50,71 & 107,18 & 23,72 & 451,78 \\
\hline \multirow{5}{*}{ A2 } & Mundaú Cond. Clube & 86,60 & 20,08 & 0 & 0 & 237,52 & 55,07 & 107,18 & 24,85 & 431,30 \\
\hline & Setai & 0 & 0 & 0 & 0 & 215,46 & 53,07 & 190,46 & 46,92 & 405,92 \\
\hline & Sangiovese & 12,59 & 5,99 & 6,7 & 3,19 & 89,01 & 42,35 & 101,89 & 48,48 & 210,59 \\
\hline & Spazio Vitalle & 21,11 & 20,39 & 0 & 0 & 21,80 & 21,05 & 60,63 & 58,56 & 103,54 \\
\hline & Pinot Noir & 51,41 & 22,45 & 9,61 & 4,20 & 115,63 & 50,50 & 52,33 & 22,85 & 228,98 \\
\hline \multirow{4}{*}{ A3 } & Amalfi & 109,95 & 21,63 & 122,74 & 24,15 & 61,05 & 12,01 & 214,43 & 42,19 & 508,17 \\
\hline & Versatile & 0 & 0 & 0 & 0 & 36,47 & 16,62 & 182,85 & 83,37 & 219,32 \\
\hline & Dilma Paiva & 236,92 & 16,95 & 0 & 0 & 213,91 & 15,30 & 946,89 & 67,74 & $1.397,72$ \\
\hline & Mares do Sul & 30,77 & 10,28 & 0 & 0 & 107,62 & 35,95 & 160,93 & 53,77 & 299,32 \\
\hline
\end{tabular}

Tabela 3 - Distribuição dos grupos de lazer por pavimentos do grupamento A1

\begin{tabular}{|l|l|l|l|l|l|l|l|l|}
\cline { 2 - 10 } \multicolumn{1}{c|}{} & I & J & A & C & I & J & A & C \\
\hline COB & & & & & & & & \\
\hline MEZ & & & & & & & & \\
\hline Pil/Ter & 2 & & 2 & 3 & 3 & & 2 & 2 \\
\hline SUB & & & & & & & & \\
\hline OUT & & & & & & & & \\
\hline & \multicolumn{2}{|l|}{$\begin{array}{l}\text { Cond. P. P. } \\
\text { das Águas }\end{array}$} & 7 & $\begin{array}{l}\text { Cond. P. P. } \\
\text { das Marés }\end{array}$ & 7 \\
\cline { 2 - 7 }
\end{tabular}

A piscina adulto ocorreu em todos os edifícios do grupo, inserida de maneira semelhante, na extremidade das áreas de lazer e no pavimento de implantação. O salão de festas foi o ambiente do lazer compartilhado de maior ocorrência, presente em 4 dos empreendimentos. O Ed. Setai não possui salão de festas, porém o espaço gourmet é maior do que 3 dos salões de festas encontrados neste grupo, cumprindo a função do salão de festas (Figura 2).

O grupo lazer adulto possui a maior área construída, seguida pelo grupo lazer compartilhado (Tabela 2). Os ambientes de lazer apresentam-se juntos e agrupados a um dos lados da guarita, no pilotis. A piscina do grupo lazer adulto ocupa a extremidade da área de lazer seguida pelos outros ambientes, primeiro os do grupo compartilhado e depois os dos grupos infantil e juvenil.

O Ed. Setai apresenta o maior índice de área de lazer por morador (1,84 m²/morador) e o Mundaú Cond. Clube, o menor (0,44 m²/morador), assemelhando-se aos condomínios do grupo A1.

O grupo A3 (UH de $51 \mathrm{~m}^{2}$ a 70 m², composto por 4 edifícios isolados das tipologias híbridas 2 e 3 dormitórios) apresenta áreas de lazer diferentes, porém com várias similaridades. Os ambientes dos grupos lazer infantil e juvenil ocorrem apenas no pavimento térreo. O ambiente infantil de maior ocorrência é o playground. Há ambiente do grupo lazer juvenil em apenas um dos edifícios. Os ambientes dos grupos lazer adulto e compartilhado ocorrem no pavimento pilotis/térreo e cobertura (Tabela 5). O ambiente adulto de maior 
ocorrência é o espaço fitness. O grupo lazer compartilhado é o que possui mais ambientes, são 8 diferentes, e o ambiente com maior ocorrência é a praça, presente em 3 edifícios do grupo, como no Ed. Amalfi (Figura 3).

O grupo lazer compartilhado apresentou a maior área construída do grupo A3 (Tabela 2).

O edifício com maior índice de lazer foi o Dilma Paiva (1,74 m²/morador), devido à grande área construída que inclui a quadra poliesportiva descoberta - isso interferiu decisivamente na média do grupo; e o menor, o Versatile $\left(0,65 \mathrm{~m}^{2} /\right.$ morador $)$.

Figura 1 - Área de lazer do Cond. P. P. das Águas - grupo A1

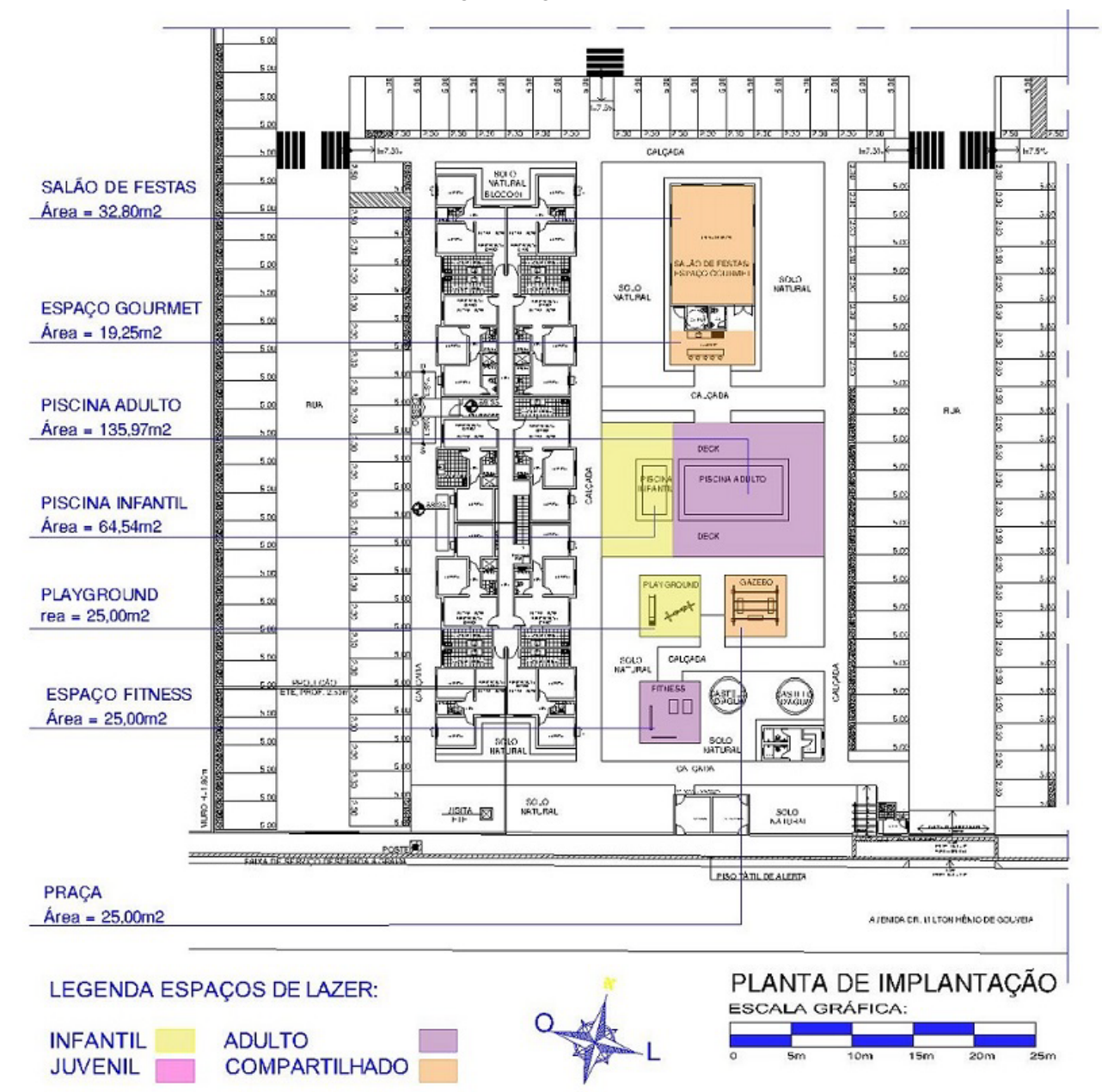

Tabela 4 - Distribuição dos grupos de lazer por pavimentos do grupamento A2

\begin{tabular}{|c|c|c|c|c|c|c|c|c|c|c|c|c|c|c|c|c|c|c|c|c|}
\hline & I & $\bar{J}$ & $\mathrm{~A}$ & C & I & $\mathrm{J}$ & $\mathrm{A}$ & $\mathrm{C}$ & I & $\mathrm{J}$ & $\mathrm{A}$ & $\mathrm{C}$ & I & $\bar{J}$ & $\mathrm{~A}$ & $\mathrm{C}$ & I & $\mathrm{J}$ & $\mathrm{A}$ & $\mathrm{C}$ \\
\hline COB & & & & & & & 3 & 2 & & & & & & & & & & & & \\
\hline MEZ & & & & & & & & & & & & & & & & & & & & \\
\hline Pil/Ter & 2 & & 2 & 2 & & & & 1 & 2 & 1 & 6 & 2 & 1 & & 1 & 2 & 2 & 1 & 5 & 2 \\
\hline SUB & & & & & & & & & & & & & & & & & & & & \\
\hline OUT & & & & & & & & & & & & & & & & & & & & \\
\hline & $\begin{array}{l}\mathrm{Mu} \\
\mathrm{Cor} \\
\mathrm{Clu}\end{array}$ & & & 6 & Se & & & 6 & & ior & & 11 & & & & 4 & & $\mathrm{~N}$ & & 10 \\
\hline
\end{tabular}


Figura 2 - Área de lazer do Edifício Setai - grupo A2

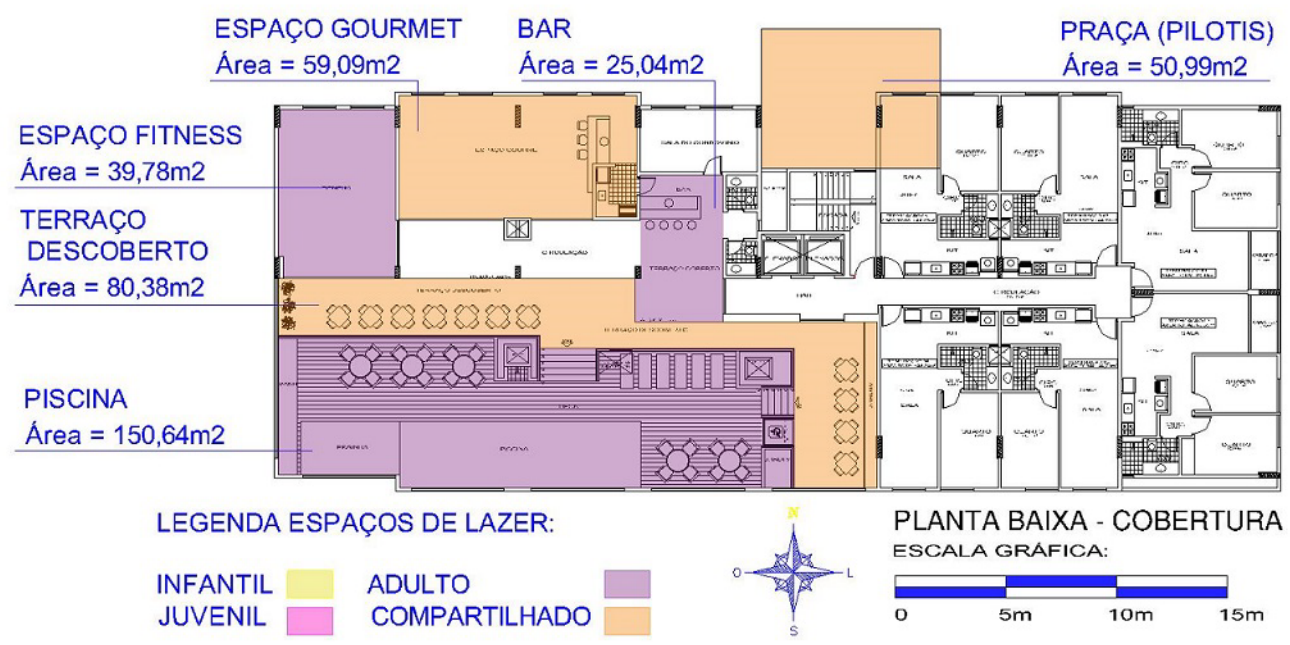

Tabela 5 - Distribuição dos grupos de lazer por pavimentos do grupamento A3

\begin{tabular}{|l|l|l|l|l|l|l|l|l|l|l|l|l|l|l|l|l|}
\cline { 2 - 12 } \multicolumn{1}{c|}{} & I & J & A & C & I & J & A & C & I & J & A & C & I & J & A & C \\
\hline COB & & & & & & & 1 & 2 & & & & & & & 2 & 2 \\
\hline MEZ & & & & & & & & & & & & & & & & \\
\hline Pil/Ter & 2 & 2 & 1 & 3 & & & & 1 & 2 & & 3 & 6 & 2 & & 1 & 1 \\
\hline SUB & & & & & & & & & & & & & & & & \\
\hline OUT & & & & & & & & & & & & & & & & \\
\hline
\end{tabular}

Figura 3 - Áreas de lazer do Edifício Amalfi - grupo A3

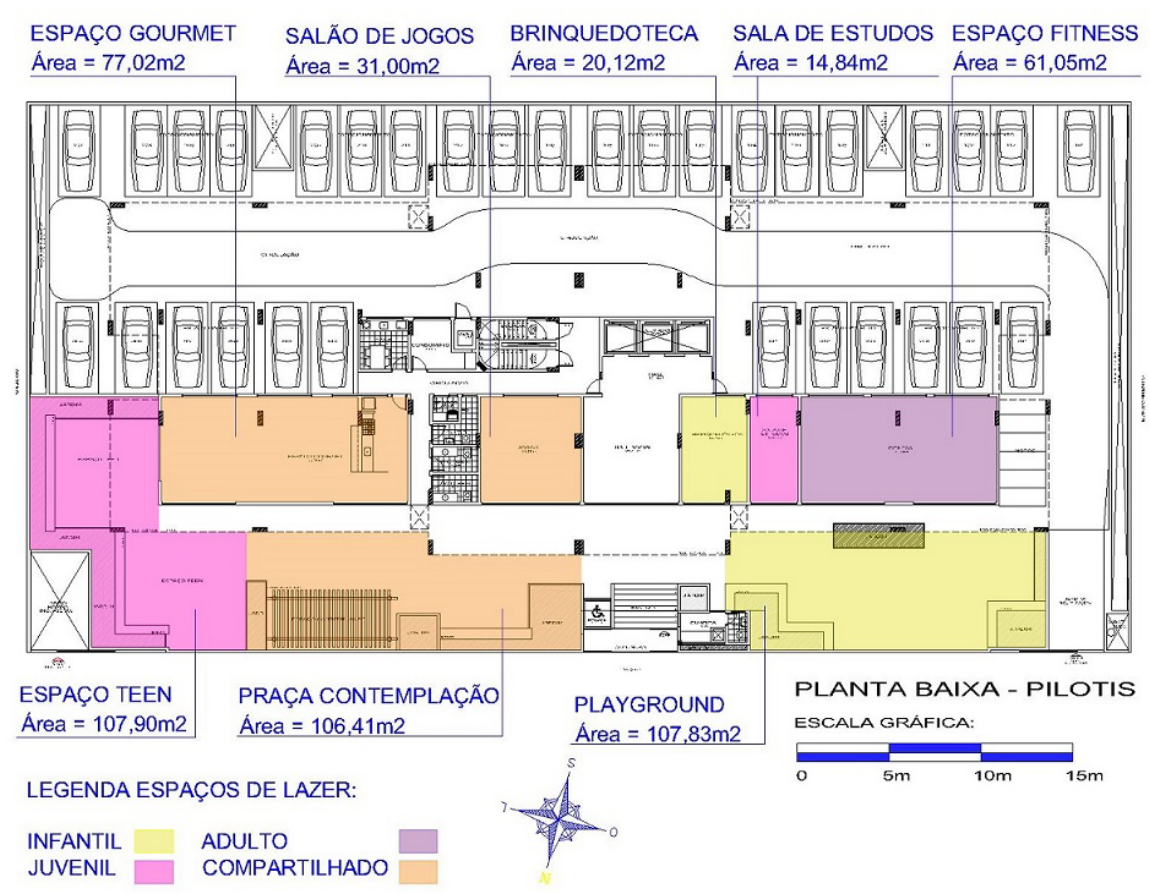


No grupamento A, a maioria das áreas de lazer ocorreu no pavimento pilotis/térreo. As áreas de lazer com piscina adulto possuem os outros ambientes de lazer organizados em torno dela, primeiro os do grupo lazer compartilhado e depois os outros, inclusive os do grupo lazer adulto. A maior área construída do grupamento A é do grupo lazer adulto, ficando o lazer compartilhado em segundo lugar. O grupo lazer juvenil é pouco significativo ou inexistente (Figura 4).

O maior índice de lazer foi do Ed. Setai (1,84 m²/morador), seguido pelo Ed. Dilma Paiva (1,74 m²/morador), e o menor do Cond. Parque Paraíso das Águas (0,23 m²/morador). Verificou-se que a média desse índice por grupo foi muito baixa no grupo A1, formado por condomínios de apartamentos de menor área das tipologias de 1 e 2 dormitórios; e semelhantes nos grupos A2 e A3, formados por edifícios isolados de apartamentos de áreas medianas, com exceção dos edifícios Setai e Dilma Paiva (Tabela 6). A média final do índice de lazer do grupamento A foi a mais baixa dos três grupamentos $\left(0,90 \mathrm{~m}^{2} /\right.$ morador $)$.

\section{Caracterização das áreas de lazer: grupamento B}

O grupamento B, com 9 empreendimentos divididos em 3 grupos (B1, B2 e B3), pode ser dividido em 2 subgrupos com mais similaridades, segundo a localização das áreas de lazer. O primeiro subgrupo com os empreendimentos que apresentam áreas de lazer nos pavimentos térreo/pilotis e cobertura, contendo 4 edifícios, e o segundo subgrupo com áreas de lazer apenas no pavimento térreo/pilotis, contendo 4 edifícios e 1 condomínio (Residencial Alto das Alamedas).

\section{Figura 4 - Distribuição das áreas de lazer do grupamento A}

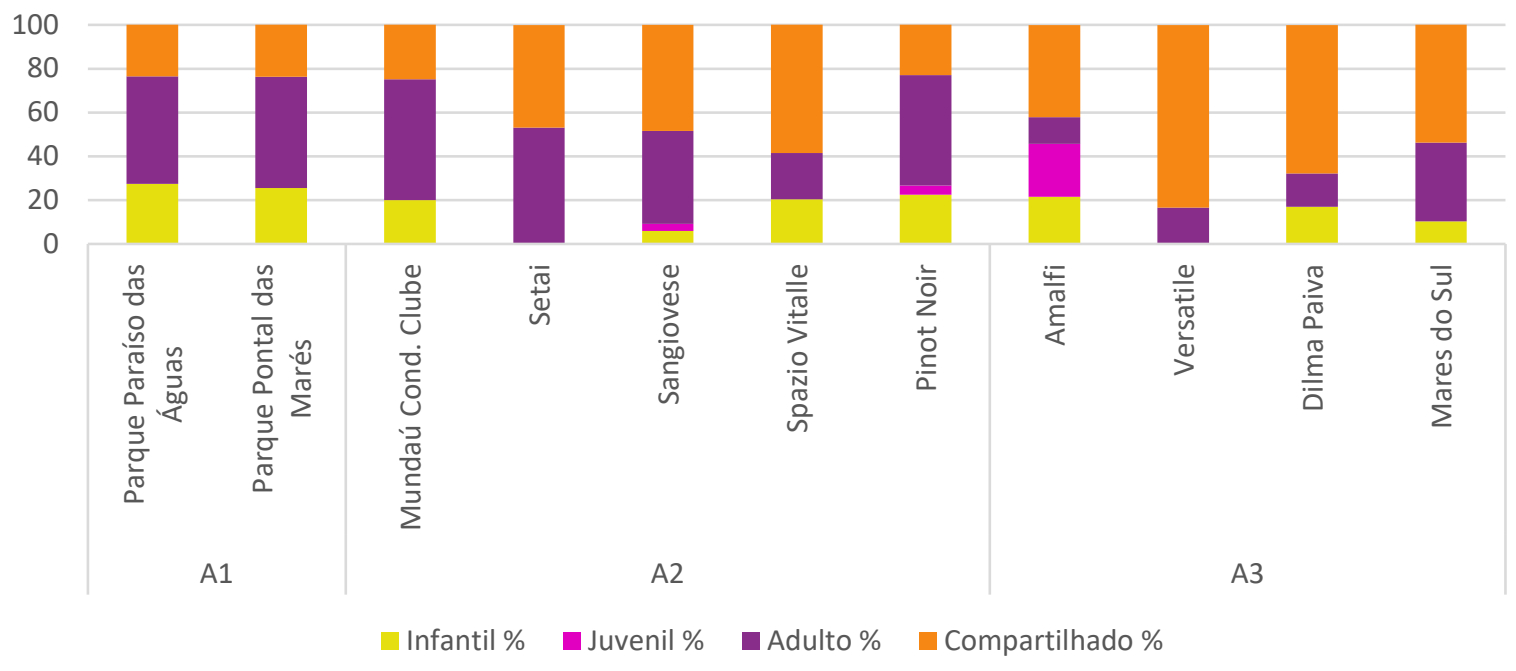

Tabela 6 - Índice de lazer dos condomínios e edifícios do grupamento A

\begin{tabular}{|c|c|c|c|c|c|}
\hline Grupo & $\begin{array}{l}\text { Condomínio/ } \\
\text { Edifício }\end{array}$ & $\begin{array}{c}\text { Área de } \\
\text { Lazer } \\
\left(\mathbf{m}^{2}\right) \\
\end{array}$ & $\begin{array}{c}\mathrm{N}^{0} \text { de } \\
\text { Moradores } \\
\text { (Provável) } \\
\end{array}$ & $\begin{array}{c}\text { Índice de } \\
\text { Lazer } \\
\text { (m²/morad.) } \\
\end{array}$ & $\begin{array}{c}\text { Média do } \\
\text { I. L. } \\
\text { (m²/morad.) }\end{array}$ \\
\hline \multirow{2}{*}{ A1 } & Cond. P. P. das Águas & 327,56 & 1.386 & 0,23 & \multirow{2}{*}{0,35} \\
\hline & Cond. P. P. das Marés & 451,78 & 960 & 0,47 & \\
\hline \multirow{5}{*}{ A2 } & Mundaú Cond. Clube & 431,30 & 960 & 0,44 & \multirow{5}{*}{1,04} \\
\hline & Setai & 405,92 & 220 & 1,84 & \\
\hline & Sangiovese & 210,59 & 252 & 0,83 & \\
\hline & Spazio Vitalle & 103,54 & 98 & 1,05 & \\
\hline & Pinot Noir & 228,98 & 220 & 1,04 & \\
\hline \multirow{4}{*}{ A3 } & Amalfi & 508,17 & 576 & 0,88 & \multirow{4}{*}{1,01} \\
\hline & Versatile & 219,32 & 336 & 0,65 & \\
\hline & Dilma Paiva & $1.397,72$ & 800 & 1,74 & \\
\hline & Mares do Sul & 299,32 & 388 & 0,77 & \\
\hline \multicolumn{5}{|c|}{ Médida final do grupamento A } & 0,9 \\
\hline
\end{tabular}


O grupo B1 (UH entre $51 \mathrm{~m}^{2}$ e $70 \mathrm{~m}^{2}$ a $71 \mathrm{~m}^{2}$ e $100 \mathrm{~m}^{2}$, híbrido com 2 edifícios, com apartamentos híbridos de 2 e 3 dormitórios) apresentou muitas diferenças nas áreas de lazer, principalmente porque um dos edifícios possui todos os ambientes de lazer no pavimento térreo/pilotis e o outro entre o térreo/pilotis e o pavimento cobertura.

Os ambientes dos grupos lazer infantil e juvenil ocorreram no térreo/pilotis. Os grupos lazer adulto e lazer compartilhado ocorreram nos dois pavimentos (Tabela 8). O acesso a dois ambientes do lazer adulto do Ed. Luna Dorata é prejudicado porque ocorre pelo salão de festas (Figura 5).

A maior área dos ambientes de lazer é do grupo lazer compartilhado, seguido pelo lazer adulto (Tabela 7). Os índices de lazer do grupo B1 são semelhantes: 0,60 m²/morador e 0,65 m²/morador.

O grupo B2 (UH entre $71 \mathrm{~m}^{2}$ e $100 \mathrm{~m}^{2}$, com 5 edifícios e apartamentos das tipologias 2 dormitórios mais reversível e 3 dormitórios) pode ser subdividido em 2 grupos, segundo suas muitas semelhanças. O primeiro grupo com 3 edifícios e áreas de lazer divididas entre os pavimentos térreo/pilotis e cobertura e o segundo com 2 edifícios com áreas de lazer apenas no pavimento térreo/pilotis.

O lazer infantil ocorre em todos os edifícios com o ambiente playground. O lazer juvenil ocorre apenas em um deles, com a sala de estudos. Os grupos de lazer infantil e juvenil ocorrem apenas no pavimento térreo/pilotis. O lazer adulto ocorre, no segundo grupo, no pavimento cobertura (Tabela 9).

A piscina do grupo de lazer adulto ocorre em todos os edifícios, e possui áreas maiores quando localizadas na cobertura. O ambiente do lazer compartilhado que ocorre com maior frequência nos edifícios do primeiro grupo é o salão de festas e do segundo, a praça, o terraço descoberto e o espaço gourmet (Figura 6).

A maior área construída em todos os edifícios é a do grupo lazer compartilhado, seguido pelo grupo lazer adulto. O lazer juvenil surge em apenas um deles; e o lazer infantil está ausente em dois outros (Tabela 7).

O maior índice de área de lazer por morador é do Ed. Personale (1,02 m²/morador); e o menor, do Ed. Iluminatto (0,42 $\mathrm{m}^{2} /$ morador).

O grupo B3 (UH entre $71 \mathrm{~m}^{2}$ e $100 \mathrm{~m}^{2}$ a $101 \mathrm{~m}^{2}$ e $150 \mathrm{~m}^{2}$, híbrido com 1 edifício e 1 condomínio, com apartamentos da tipologia de 3 dormitórios) apresentou muitas semelhanças em suas áreas de lazer, principalmente porque as duas ocorrem no pavimento térreo/pilotis, com grande quantidade de ambientes de lazer e uma área extensa, mais de $1.500 \mathrm{~m}^{2}$, nas quais esses ambientes se localizam.

Tabela 7 - Distribuição das áreas de lazer - grupo B

\begin{tabular}{|c|c|c|c|c|c|c|c|c|c|c|}
\hline \multirow{3}{*}{ Grupo } & \multirow{3}{*}{ Condomínio/Edifício } & \multicolumn{8}{|c|}{ Grupo de lazer } & \multirow{3}{*}{$\frac{\text { Total }}{\mathbf{m}^{2}}$} \\
\hline & & \multicolumn{2}{|c|}{ Infantil } & \multicolumn{2}{|c|}{ Juvenil } & \multicolumn{2}{|c|}{ Adulto } & \multicolumn{2}{|c|}{ Compartilhado } & \\
\hline & & m2 & $\%$ & $\mathrm{~m}^{2}$ & $\%$ & $\mathrm{~m}^{2}$ & $\%$ & $\mathrm{~m}^{2}$ & $\%$ & \\
\hline \multirow{2}{*}{ B1 } & Dulce Tenório & 18,87 & 9,50 & 16,10 & 8,10 & 78,97 & 39,78 & 84,59 & 42,60 & 198,53 \\
\hline & Luna Dorata & 18,28 & 7,39 & 0 & 0 & 48,94 & 19,77 & 180,27 & 72,84 & 247,49 \\
\hline \multirow{5}{*}{ B2 } & Life & 26,70 & 6,40 & 11,11 & 2,66 & 124,20 & 29,79 & 254,85 & 61,13 & 416,86 \\
\hline & Vitta & 0 & 0 & 0 & 0 & 57,50 & 23,76 & 184,42 & 76,23 & 241,92 \\
\hline & Índico & 51,40 & 39,49 & 0 & 0 & 25,11 & 19,29 & 53,65 & 41,22 & 130,16 \\
\hline & Personale & 0 & 0 & 0 & 0 & 47,35 & 20,22 & 186,71 & 79,77 & 234,06 \\
\hline & Iluminatto & 18,24 & 29,65 & 0 & 0 & 19,09 & 31,03 & 24,19 & 39,32 & 61,52 \\
\hline \multirow{2}{*}{ B3 } & Mirante C. Stratégia & 248,36 & 13,19 & 26,76 & 1,42 & 645,26 & 34,27 & 962,02 & 51,10 & $1.882,40$ \\
\hline & Res. Alto das Alamedas & 350,51 & 14,39 & 86,87 & 3,57 & 921,94 & 37,85 & $1.076,43$ & 44,19 & $2.435,75$ \\
\hline
\end{tabular}

Tabela 8 - Distribuição dos grupos de lazer por pavimentos do grupamento B1

\begin{tabular}{|l|l|l|l|l|l|l|l|l|}
\cline { 2 - 10 } \multicolumn{1}{c|}{} & I & J & A & C & I & J & A & C \\
\hline COB & & & & & & & 3 & 3 \\
\hline MEZ & & & & & & & & \\
\hline Pil/Ter & 1 & 1 & 2 & 2 & 1 & & & 1 \\
\hline SUB & & & & & & & & \\
\hline OUT & & & & & & & & \\
\hline & $\begin{array}{l}\text { Dulce } \\
\text { Tenório }\end{array}$ & 6 & \multicolumn{2}{l}{ Luna Dorata } & 8 \\
\cline { 2 - 8 }
\end{tabular}


Figura 5 - Áreas de lazer do Edifício Luna Dorata - grupo B1

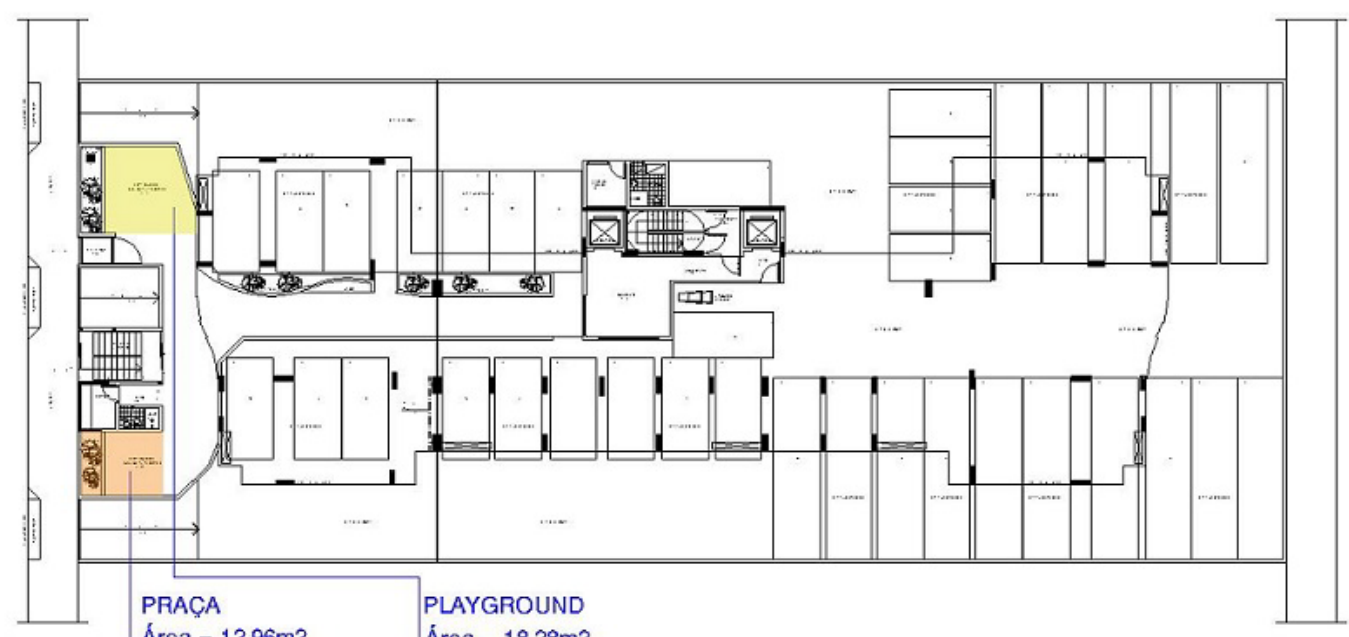

Área $=12,96 \mathrm{~m} 2 \quad$ Área $=18,28 \mathrm{~m} 2$

PLANTA BAIXA - PILOTIS

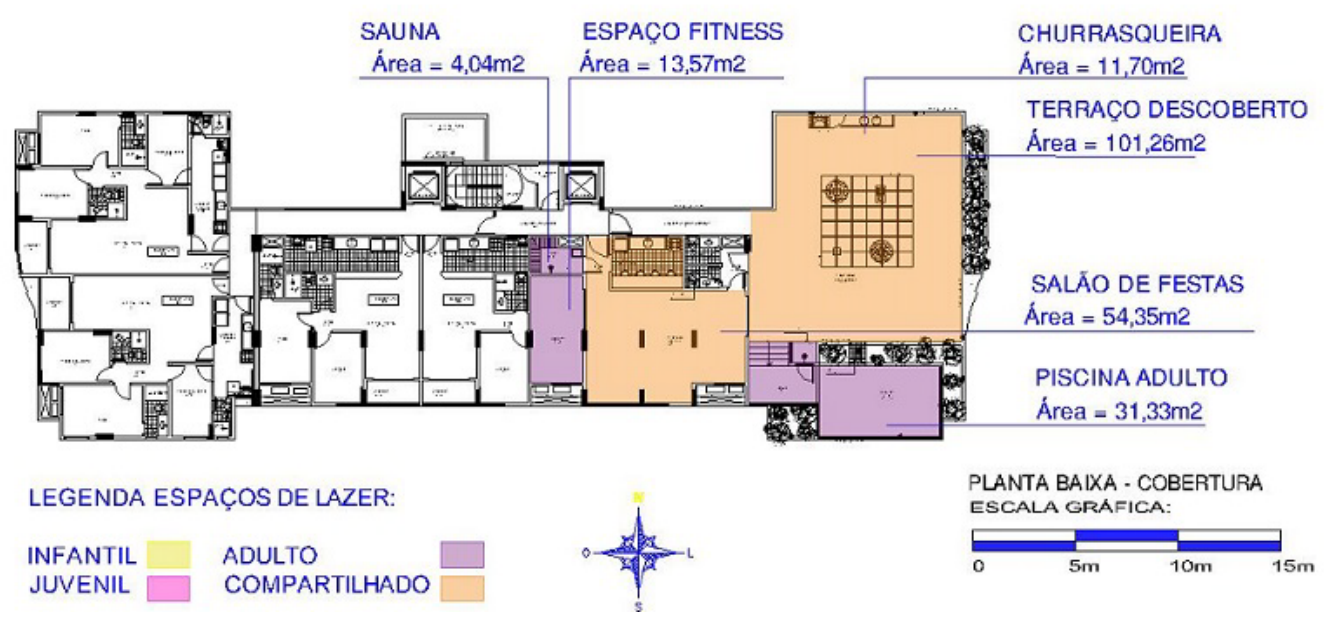

Tabela 9 - Distribuição dos grupos de lazer por pavimentos do grupamento B2

\begin{tabular}{|l|l|l|l|l|l|l|l|l|l|l|l|l|l|l|l|l|l|l|l|l|l|}
\cline { 2 - 15 } \multicolumn{1}{c|}{} & I & J & A & C & I & J & A & C & I & J & A & C & I & J & A & C & I & J & A & C \\
\hline COB & & & 6 & 2 & & & 1 & 3 & & & & & & & 1 & 3 & & & & \\
\hline MEZ & & & & & & & & & & & & & & & & & & & & \\
\hline Pil/Ter & 2 & 1 & & 2 & & & & 1 & 1 & & 1 & 1 & & & & 1 & 1 & & 1 & 1 \\
\hline SUB & & & & & & & & & & & & & & & & & & & & \\
\hline OUT & & & & & & & & & & & & & & & & & & & & \\
\hline
\end{tabular}


Figura 6 - Áreas de lazer do Edifício lluminatto: grupo B2

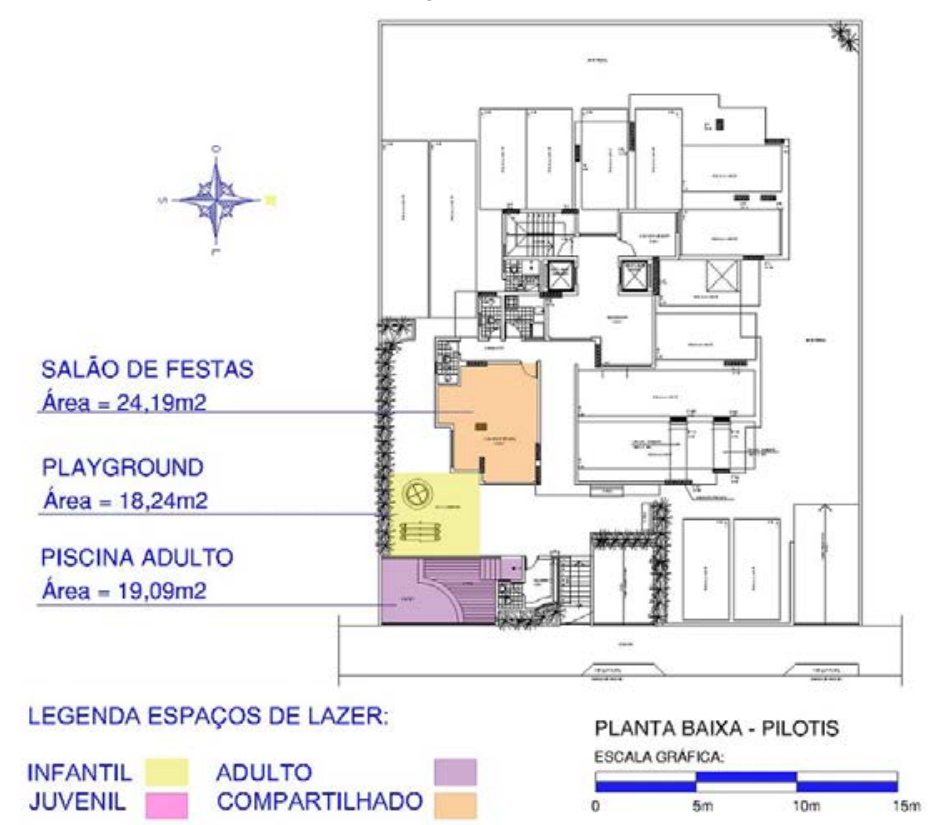

O lazer infantil apresentou ambientes iguais ocorrendo nos dois empreendimentos: piscina infantil, playground e brinquedoteca. O playground, nos dois casos, foram os maiores de toda a amostra. O lazer juvenil apresentou mais de um ambiente. O lazer adulto apresentou 9 tipos de ambientes, as piscinas com mais de 250 $\mathrm{m}^{2}$, e surgiram ambientes novos como: piscina senadinho, pista de cooper, spa zen e redário, como observado por Nigri (2006) e Sampaio (2010), no Rio de Janeiro e São Paulo, respectivamente. O lazer compartilhado apresentou 7 tipos de ambientes, alguns se repetindo no mesmo empreendimento, como a praça que ocorreu 4 vezes no Mirante Clube Stratégia e 10 vezes no Res. Alto das Alamedas (Tabela 10). Nesse último, houve a preocupação de proporcionar a visualização do ambiente externo para os usuários de quase todos os ambientes de lazer (Figura 7).

Os quatro grupos de lazer ocorreram nos 2 empreendimentos e suas áreas construídas foram semelhantes, o que demonstra não haver diferença entre condomínio e edifício isolado, quanto aos itens de lazer. As áreas de lazer ocupam metade da área do térreo/pilotis.

A maior área construída do grupamento B foi do grupo lazer compartilhado, ficando o grupo lazer adulto em segundo lugar. O grupo lazer juvenil foi pouco expressivo ou inexistente (Tabela 7 e Figura 8).

Os índices de áreas de lazer do grupamento B foram muito variáveis, o maior foi do Edif. Mirante Clube Stratégia (1,96 m²/morador), seguido pelo Condomínio Residencial Alto das Alamedas (1,69 m²/morador) e os menores do Edif. Iluminatto (0,42 $\mathrm{m}^{2} /$ morador), seguido pelo Edif. Índico (0,54 $\mathrm{m}^{2} /$ morador).

A média do índice de lazer dos grupos B1 e B2 foi baixa, e a do grupo B3 foi bastante elevada, tanto no edifício isolado quanto no condomínio de três torres, devido, possivelmente, ao padrão construtivo elevado de ambos (Tabela 11). A média final do grupamento B foi de 1,06 m²/morador.

\section{Caracterização das áreas de lazer: grupamento $C$}

O grupamento C, com 11 empreendimentos divididos em 2 grupos (C1 e C2), apresentou muitas similaridades, tanto em relação à configuração dos ambientes de lazer, quanto à configuração dos quatro grupos de lazer.

Os ambientes do grupo lazer infantil ocorreram no pavimento térreo/pilotis em todos os componentes desse grupamento, com maior frequência para a brinquedoteca. O lazer juvenil ocorreu no térreo ou no mezanino, em 8 componentes do grupo, com maior frequência para a sala de estudos. Os ambientes de lazer adulto e compartilhado ocorreram em todos os componentes do grupamento, em vários pavimentos, com maior frequência para o espaço fitness, no lazer adulto, praça e espaço gourmet, no lazer compartilhado.

Verificaram-se 5 tipos diferentes de localização da área de lazer: no pavimento térreo/pilotis com o ambiente piscina adulto, em 3 componentes da amostra; no pavimento térreo/pilotis sem piscina, em outros 3 
componentes; no pavimento térreo/pilotis e no mezanino, em 3 outros componentes; nos pavimentos térreo/pilotis e cobertura, em 1 componente; e nos pavimentos térreo/pilotis, subsolo 1, subsolo 2 e outros, em 1 outro componente. De acordo com as localizações das áreas de lazer, elas apresentaram de 1 a 3 blocos com ambientes de lazer.

O grupo C1 (UH de $101 \mathrm{~m}^{2}$ a $150 \mathrm{~m}^{2}$, com 8 edifícios e 1 condomínio, com apartamentos das tipologias de 3 dormitórios, 3 dormitórios mais reversível, 3 e 4 dormitórios e 4 dormitórios) pode ser dividido em 5 tipos, segundo a localização das áreas de lazer, e dentro de cada um desses tipos, visualizaram-se algumas similaridades entre os componentes.

Tabela 10 - Distribuição dos grupos de lazer por pavimentos do grupamento B3

\begin{tabular}{|l|c|c|c|c|c|c|c|c|}
\cline { 2 - 10 } \multicolumn{1}{c|}{} & I & J & A & C & I & J & A & C \\
\hline COB & & & & & & & & \\
\hline MEZ & & & & & & & & \\
\hline Pil/Ter & 3 & 2 & 6 & 9 & 3 & 2 & 7 & 16 \\
\hline SUB & & & & & & & & \\
\hline OUT & & & & & & & 1 & \\
\hline & $\begin{array}{l}\text { Mirante C. } \\
\text { Stratégia }\end{array}$ & 20 & $\begin{array}{l}\text { Res. Alto das } \\
\text { Alamedas }\end{array}$ & 29 \\
\hline
\end{tabular}

Figura 7 - Áreas de lazer do Res. Alto das Alamedas: grupo B3

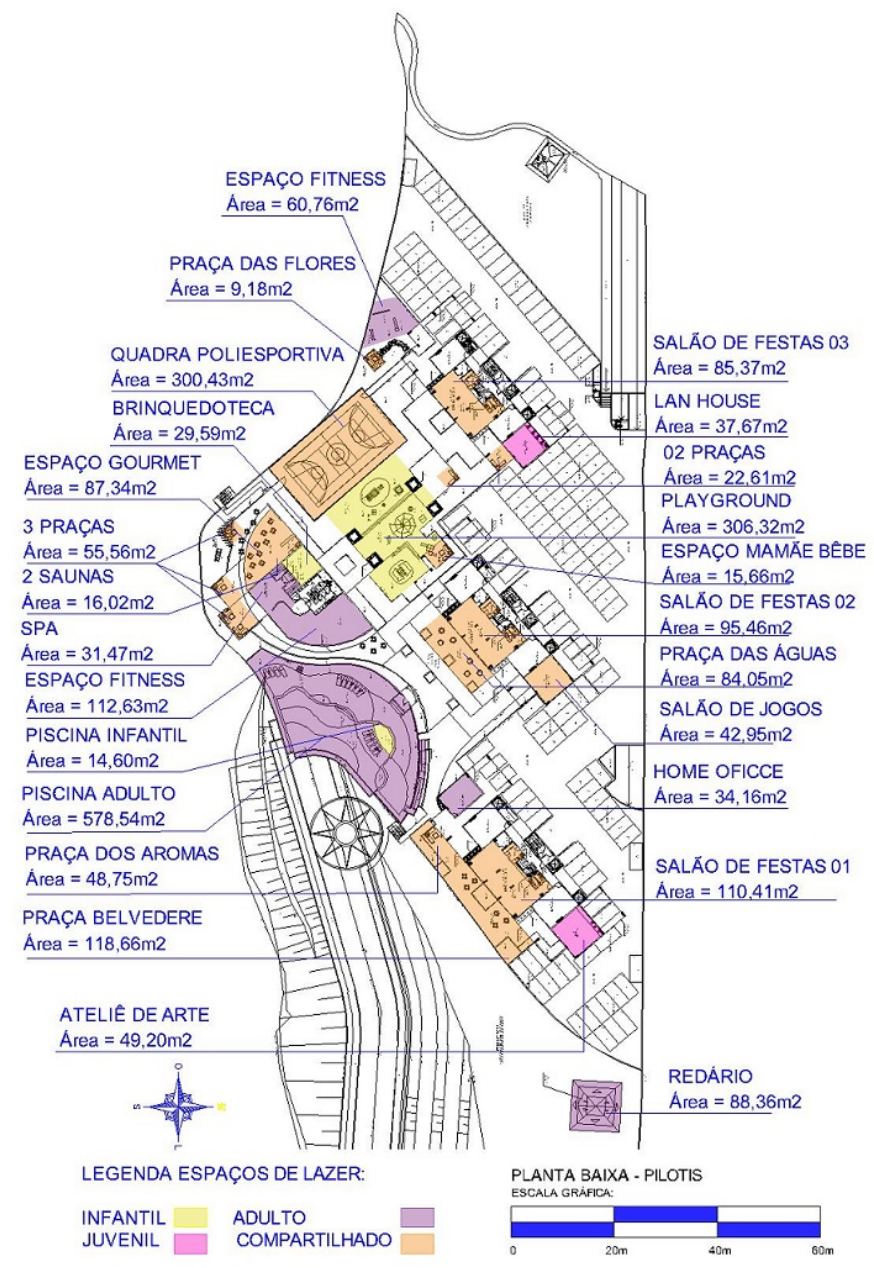


Figura 8 - Distribuição das áreas de lazer do grupamento B

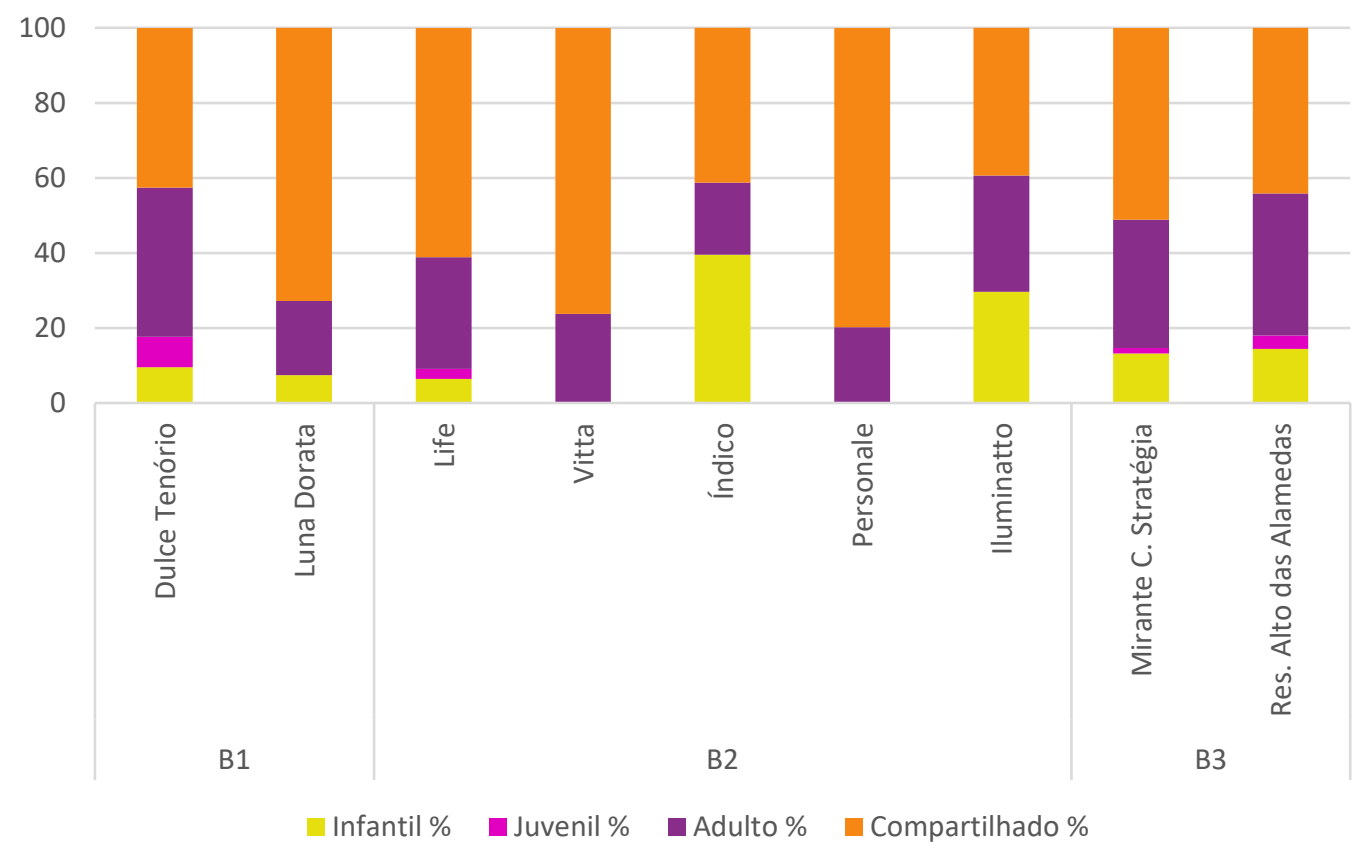

Tabela 11 - Índice de lazer dos edifícios e condomínios do grupamento B

\begin{tabular}{|c|c|c|c|c|c|}
\hline Grupo & Condomínio/Edifício & $\begin{array}{c}\text { Área de } \\
\text { lazer } \\
\left(\mathrm{m}^{2}\right)\end{array}$ & $\begin{array}{c}\mathrm{N}^{0} \text { de } \\
\text { moradores } \\
\text { (Provável) }\end{array}$ & \begin{tabular}{|c|}
$\begin{array}{c}\text { Índice de } \\
\text { lazer } \\
\text { (m²/morad.) }\end{array}$ \\
\end{tabular} & $\begin{array}{c}\text { Média do } \\
\text { I. L. } \\
\text { (m²/morad.) }\end{array}$ \\
\hline \multirow{2}{*}{ B1 } & Dulce Tenório & 198,53 & 330 & 0,60 & \multirow{2}{*}{0,625} \\
\hline & Luna Dorata & 247,49 & 378 & 0,65 & \\
\hline \multirow{5}{*}{ B2 } & Life & 416,86 & 456 & 0,91 & \multirow{5}{*}{0,76} \\
\hline & Vitta & 241,92 & 260 & 0,93 & \\
\hline & Índico & 130,16 & 240 & 0,54 & \\
\hline & Personale & 234,06 & 228 & 1,02 & \\
\hline & Iluminatto & 61,52 & 145 & 0,42 & \\
\hline \multirow{2}{*}{ B3 } & Mirante Clube Stratégia & $1.882,40$ & 960 & 1,96 & \multirow{2}{*}{1,82} \\
\hline & Res. Alto das Alamedas & $2.435,75$ & 1.440 & 1,69 & \\
\hline \multicolumn{5}{|c|}{ Médida Final do Grupamento B } & 1,06 \\
\hline
\end{tabular}

Tabela 12 - Distribuição das áreas de lazer: grupo C

\begin{tabular}{|c|c|c|c|c|c|c|c|c|c|c|}
\hline \multirow{3}{*}{ Grupo } & \multirow{3}{*}{ Condomínio/Edifício } & \multicolumn{8}{|c|}{ Grupo de lazer } & \multirow{3}{*}{$\frac{\text { Total }}{\mathbf{m}^{2}}$} \\
\hline & & \multicolumn{2}{|c|}{ Infantil } & \multicolumn{2}{|c|}{ Juvenil } & \multicolumn{2}{|c|}{ Adulto } & \multicolumn{2}{|c|}{ Compartilhado } & \\
\hline & & $\mathbf{m}^{2}$ & $\%$ & $\mathrm{~m}^{2}$ & $\%$ & $\mathrm{~m}^{2}$ & $\%$ & $\mathbf{m}^{2}$ & $\%$ & \\
\hline \multirow{9}{*}{ C1 } & One & 42,26 & 14,15 & 25,92 & 8,68 & 49,40 & 16,54 & 180,98 & 60,61 & 298,56 \\
\hline & Gran Marine & 201,19 & 9,08 & 113,95 & 5,14 & 974,58 & 43,99 & 925,76 & 41,79 & $2.215,48$ \\
\hline & Hit & 36,52 & 13,56 & 13,26 & 4,91 & 87,12 & 32,29 & 132,88 & 49,25 & 269,78 \\
\hline & Atmosfhera & 89,23 & 31,15 & 52,48 & 18,32 & 28,74 & 10,03 & 115,96 & 40,48 & 286,41 \\
\hline & Cádiz & 33,36 & 12,12 & 0 & 0 & 65,46 & 23,79 & 176,36 & 64,09 & 275,18 \\
\hline & Prime & 27,20 & 14,30 & 0 & 0 & 21,35 & 11,23 & 141,56 & 74,46 & 190,11 \\
\hline & Syrah & 143,53 & 26,08 & 7,38 & 1,34 & 196,78 & 35,75 & 202,71 & 36,83 & 550,40 \\
\hline & Chardonnay & 11,48 & 10,45 & 3,38 & 3,08 & 56,59 & 51,53 & 38,36 & 34,93 & 109,81 \\
\hline & Classic & 42,63 & 21,57 & 0 & 0 & 80,65 & 40,81 & 74,33 & 37,61 & 197,61 \\
\hline \multirow{2}{*}{$\mathrm{C} 2$} & Double & 17,20 & 9,10 & 11,80 & 6,24 & 36,29 & 19,21 & 123,60 & 65,43 & 188,89 \\
\hline & Vitreo & 47,46 & 11,51 & 6,89 & 1,67 & 54,64 & 13,25 & 303,29 & 73,56 & 412,28 \\
\hline
\end{tabular}


O Condomínio Gran Marine apresentou o maior número de ambientes da amostra (Figura 9) e o Edifício Syrah, o maior número de ambientes dos edifícios isolados.

Os ambientes do grupo lazer infantil ocorreram em todos os componentes do grupo, no pavimento térreo/pilotis, com maior frequência para o playground e a brinquedoteca. O grupo lazer juvenil ocorreu em 6 componentes do grupo, com maior frequência para a sala de estudos. Os ambientes de lazer adulto e compartilhado ocorreram em todos os componentes, com maior frequência para o espaço fitness, no adulto, e salão de festas, no compartilhado (Tabela 13). Observa-se, porém, que os edifícios sem salão de festas possuíam espaço gourmet.

A maior área dos ambientes de lazer se deu no grupo lazer compartilhado, seguido pelo lazer adulto. Três edifícios não apresentam ambientes do grupo lazer juvenil (Tabela 12).

Verificaram-se 5 tipos diferentes de localização da área de lazer: no pavimento térreo/pilotis, com piscina adulto; no pavimento térreo/pilotis, sem piscina; no pavimento térreo/pilotis e no mezanino; nos pavimentos térreo/pilotis e cobertura; e nos pavimentos térreo/pilotis, subsolo 1, subsolo 2 e outros. Ambientes de lazer no pavimento mezanino foi uma novidade desse grupo, não observado nas quatro cidades pesquisadas por outros autores.

Figura 9 - Áreas de lazer do Cond. Gran Marine: grupo C1

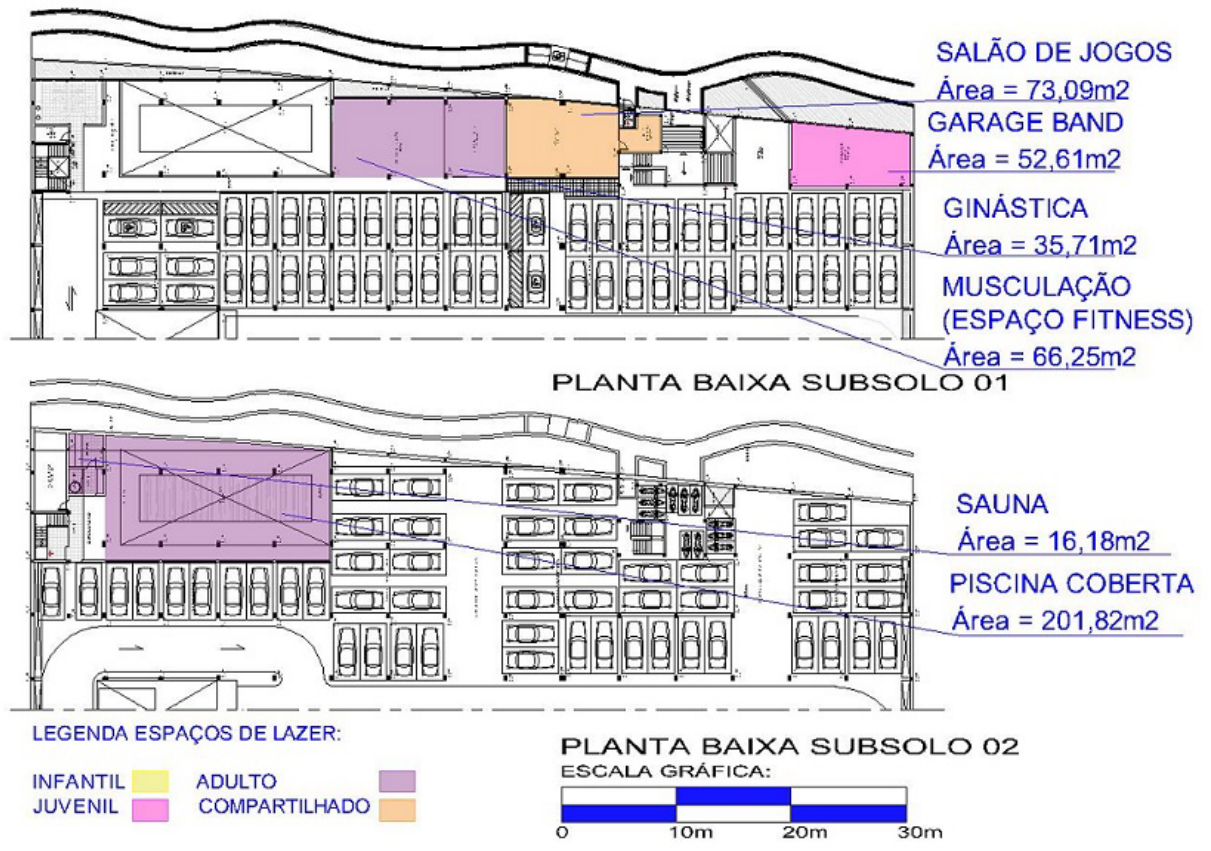

Tabela 13 - Distribuição dos grupos de lazer por pavimentos do grupamento C1

\begin{tabular}{|c|c|c|c|c|c|c|c|c|c|c|c|c|c|c|c|c|c|c|c|c|}
\hline & I & $\bar{J}$ & $\bar{A}$ & $\mathrm{C}$ & $\bar{I}$ & $\bar{J}$ & $\mathrm{~A}$ & $\bar{C}$ & $\bar{I}$ & $\bar{J}$ & $\bar{A}$ & $\mathrm{C}$ & I & $\bar{J}$ & $\bar{A}$ & $\bar{C}$ & $\bar{I}$ & $\mathrm{~J}$ & $\bar{A}$ & $\bar{C}$ \\
\hline $\mathrm{COB}$ & & & & & & & & & & & 2 & 4 & & & & & & & & \\
\hline MEZ & & 1 & 2 & 2 & & & & & & & & & & & & & & & & 1 \\
\hline Pil/Ter & 2 & & & 1 & 3 & 3 & 5 & 7 & 2 & 1 & 1 & & 2 & 1 & 1 & 2 & 1 & & 1 & \\
\hline SUB & & & & & & 1 & 4 & 1 & & & & & & & & & & & & \\
\hline \multirow[t]{3}{*}{ OUT } & & & & & & & 1 & 1 & & & & & & & & & & & & \\
\hline & \multicolumn{3}{|c|}{ One } & 8 & \multicolumn{3}{|c|}{ Gran Marine } & 26 & \multicolumn{3}{|c|}{ Hit } & 10 & \multicolumn{3}{|c|}{ Atmosfhera } & 6 & \multicolumn{3}{|c|}{ Cádiz } & 3 \\
\hline & $\mathrm{I}$ & $\mathrm{J}$ & $\mathrm{A}$ & $\mathrm{C}$ & $\mathrm{I}$ & $\overline{\mathrm{J}}$ & A & $\bar{C}$ & $\mathrm{I}$ & $\mathrm{J}$ & $\mathrm{A}$ & $\mathrm{C}$ & $\mathrm{I}$ & $\mathrm{J}$ & A & $\mathrm{C}$ & & & & \\
\hline \multicolumn{17}{|l|}{$\mathrm{COB}$} & & & & \\
\hline \multicolumn{17}{|l|}{ MEZ } & & & & \\
\hline Pil/Ter & 2 & & 1 & 4 & 4 & 1 & 8 & 6 & 1 & 1 & 5 & 1 & 2 & & 5 & 4 & & & & \\
\hline \multicolumn{17}{|l|}{ SUB } & & & & \\
\hline \multirow[t]{2}{*}{ OUT } & & & & & & & & & & & & & & & & & & & & \\
\hline & \multicolumn{3}{|c|}{ Prime } & 7 & \multicolumn{3}{|c|}{ Syrah } & 19 & \multicolumn{3}{|c|}{ Chardonnay } & 8 & \multicolumn{3}{|c|}{ Classic } & 11 & & & & \\
\hline
\end{tabular}


O maior índice de área de lazer por morador foi do Ed. Cádiz (1,58 m²/morador); e o menor, do Ed. Prime (0,54 $\mathrm{m}^{2} /$ morador).

O grupo C2 (UH de $151 \mathrm{~m}^{2}$ a $250 \mathrm{~m}^{2}$, com 2 edifícios das tipologias de 3 e 4 apartamentos e de 4 apartamentos), apresentou ambientes do lazer infantil no pavimento térreo/pilotis (Figura 10), com maior frequência para a brinquedoteca. Os ambientes do lazer juvenil, adulto e compartilhado ocorreram nos dois edifícios, com os ambientes sala de estudos, espaço fitness, home office, praça e espaço gourmet, no térreo/pilotis do Ed. Vitreo, e no mezanino do Ed. Double, com exceção da praça que ocorreu no térreo (Tabela 14).

A maior área dos ambientes de lazer foi do grupo lazer compartilhado, seguido pelo lazer adulto (Tabela 12). O Ed. Double apresentou área de lazer dividida entre o pavimento térreo/pilotis e o mezanino, enquanto a área do Ed. Vitreo ocupou apenas o térreo/pilotis. O primeiro dividiu a área de lazer em dois blocos, com o lazer infantil apenas no térreo/pilotis. O segundo em três blocos, um de cada lado da guarita e o terceiro entre os halls dos elevadores.

A maior área construída do grupamento C foi do grupo lazer compartilhado, ficando o lazer adulto em segundo lugar. O grupo lazer juvenil foi pouco expressivo ou inexistente (Figura 11).

Os valores dos índices de lazer foram muito oscilantes no grupo C1, o qual apresentou o maior valor (Ed. Cádiz - 1,58 $\mathrm{m}^{2} /$ morador) e o menor valor (Ed. Prime - 0,54 $\mathrm{m}^{2} /$ morador), e semelhantes no grupo C2. A média do índice de lazer do grupamento C foi de $1,11 \mathrm{~m}^{2} /$ morador, muito próxima do grupamento B (Tabela 15).

\section{Síntese dos resultados}

O grupamento A (UH até $70 \mathrm{~m}^{2}$ ) apresentou com maior frequência o ambiente playground, no lazer infantil; piscina adulto e espaço fitness, no adulto; e espaço gourmet e salão de festas fechado, no lazer compartilhado. A maioria das áreas de lazer está implantada no pavimento térreo/pilotis e a maior área construída é do lazer adulto. A média do índice de lazer do grupamento A foi de $0,54 \mathrm{~m}^{2} /$ morador - a menor dos três grupos.

Tabela 14 - Distribuição dos grupos de lazer por pavimentos do grupamento C2

\begin{tabular}{|l|c|c|c|c|c|c|c|c|}
\cline { 2 - 10 } \multicolumn{1}{c|}{} & I & J & A & C & I & J & A & C \\
\hline COB & & & & & & & & \\
\hline MEZ & & 1 & 2 & 2 & & & & \\
\hline Pil/Ter & 1 & & & 1 & 2 & 1 & 2 & 3 \\
\hline SUB & & & & & & & & \\
\hline OUT & & & & & & & & \\
\hline \multicolumn{2}{|l|}{ Double } & 7 & \multicolumn{2}{|c|}{ Vitreo } & 8 \\
\hline
\end{tabular}

Figura 10 - Áreas de lazer do - Edifício Double: grupo C2

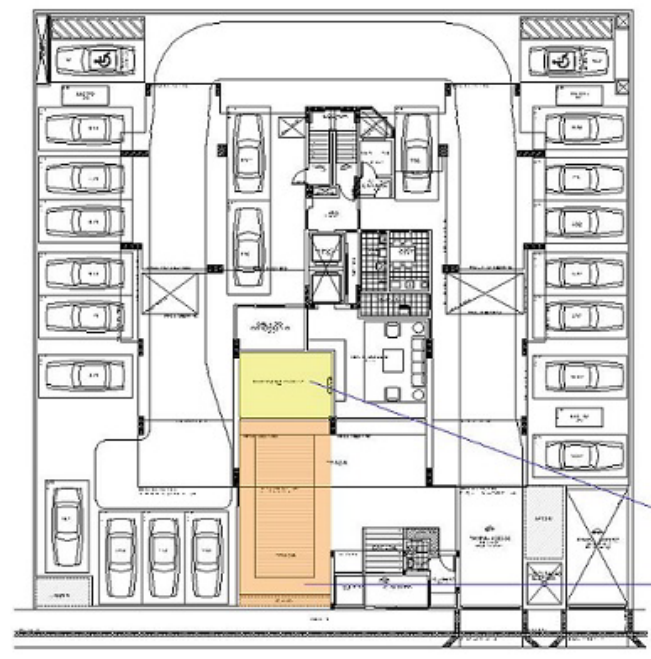

PLANTA BAIXA - PILOTIS

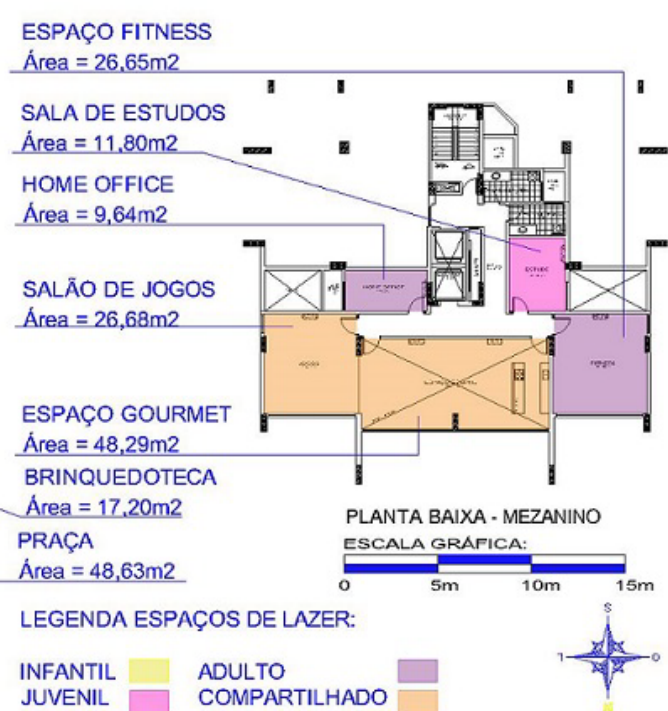




\section{Figura 11 - Distribuição das áreas de lazer do grupamento C}

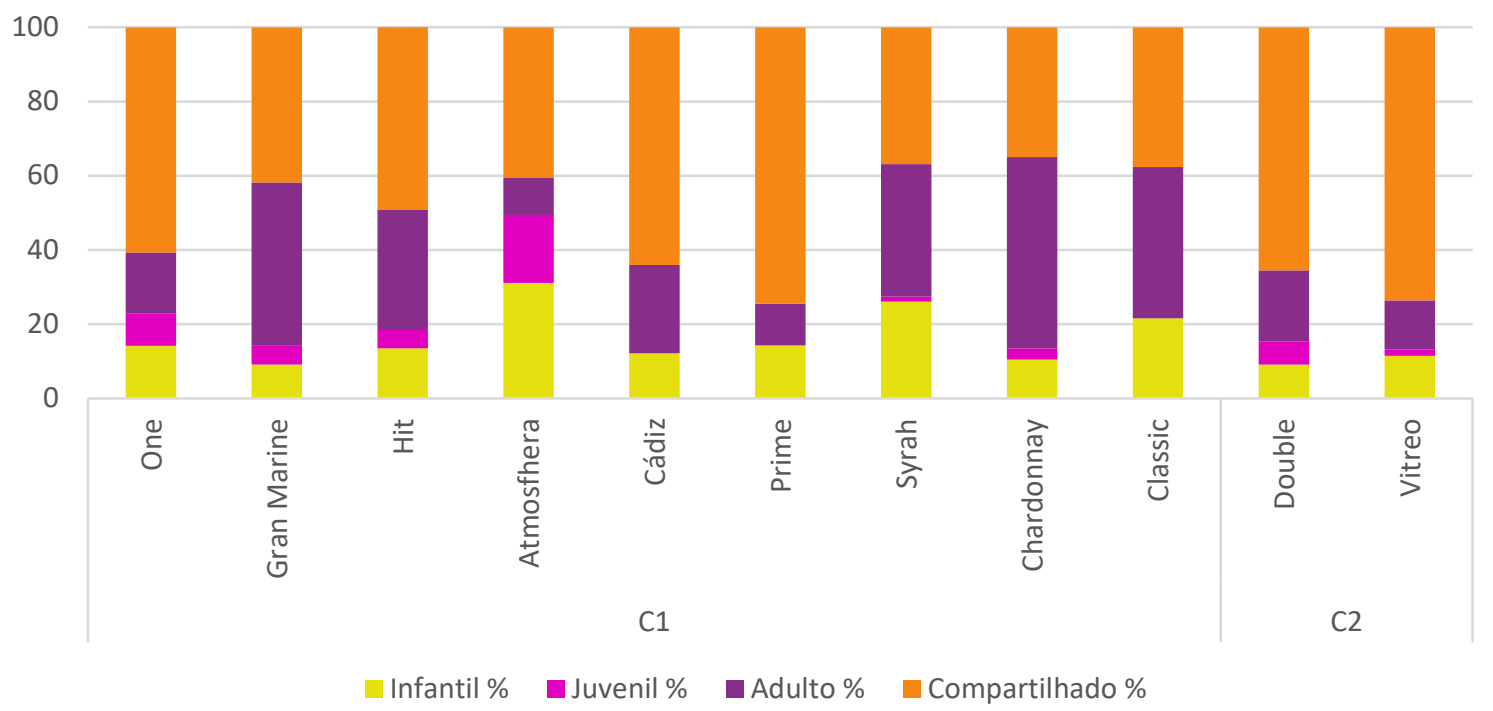

Tabela 15 - Índice de lazer dos edifícios e condomínios do grupamento $\mathrm{C}$

\begin{tabular}{|c|c|c|c|c|c|}
\hline Grupo & $\begin{array}{l}\text { Condomínio/ } \\
\text { Edifício }\end{array}$ & $\begin{array}{c}\text { Área de } \\
\text { lazer } \\
\left(\mathbf{m}^{2}\right) \\
\end{array}$ & $\begin{array}{c}\mathrm{N}^{0} \text { de } \\
\text { moradores } \\
\text { (provável) }\end{array}$ & $\begin{array}{c}\text { Índice de } \\
\text { lazer } \\
\text { (m²/morad.) } \\
\end{array}$ & $\begin{array}{c}\text { Média do } \\
\text { I. L. } \\
\text { (m²/morad.) }\end{array}$ \\
\hline \multirow{9}{*}{ C1 } & One & 298,56 & 286 & 1,04 & \multirow{9}{*}{0,87} \\
\hline & Gran Marine & 2215,48 & 1520 & 1,45 & \\
\hline & Hit & 269,78 & 266 & 1,01 & \\
\hline & Atmosfhera & 286,41 & 324 & 0,88 & \\
\hline & Cádiz & 275,18 & 174 & 1,58 & \\
\hline & Prime & 190,11 & 348 & 0,54 & \\
\hline & Syrah & 550,40 & 528 & 1,04 & \\
\hline & Chardonnay & 109,81 & 156 & 0,70 & \\
\hline & Classic & 197,61 & 304 & 0,65 & \\
\hline \multirow{2}{*}{ C2 } & Double & 188,89 & 136 & 1,38 & \multirow{2}{*}{1,36} \\
\hline & Vitreo & 412,28 & 304 & 1,35 & \\
\hline \multicolumn{5}{|c|}{ Médida Final do Grupamento C } & 1,11 \\
\hline
\end{tabular}

O grupamento B (UH de $51 \mathrm{~m}^{2}$ até $150 \mathrm{~m}^{2}$ ) também apresentou com maior frequência o ambiente playground, no grupo lazer infantil; apenas a piscina, no grupo lazer adulto; e salão de festas fechado e praça, no grupo lazer compartilhado. A maioria das áreas de lazer foi implantada no pavimento térreo/pilotis e a maior área construída foi do grupo lazer compartilhado. A média do índice de lazer por morador do grupamento B foi de $1,06 \mathrm{~m}^{2} /$ morador.

Os ambientes do grupo lazer juvenil ocorreram em menos da metade dos empreendimentos dos grupamentos A e B. Apenas os edifícios isolados apresentaram ambientes de lazer no pavimento mezanino, tanto no grupo B3 quanto no grupo C1.

O grupamento C (UH acima de $101 \mathrm{~m}^{2}$ ) apresentou com maior frequência o ambiente brinquedoteca, no grupo lazer infantil; sala de estudos, no grupo lazer juvenil; espaço fitness, no grupo lazer adulto; e espaço gourmet e praça, no grupo lazer compartilhado. A maioria das áreas de lazer foi implantada no pavimento térreo/pilotis e a maior área construída foi do lazer compartilhado. A média do índice de lazer por morador do grupamento C foi de $1,11 \mathrm{~m}^{2} /$ morador - muito próxima do grupamento B (Figura 12). 
Figura 12 - Índices de lazer por grupamentos

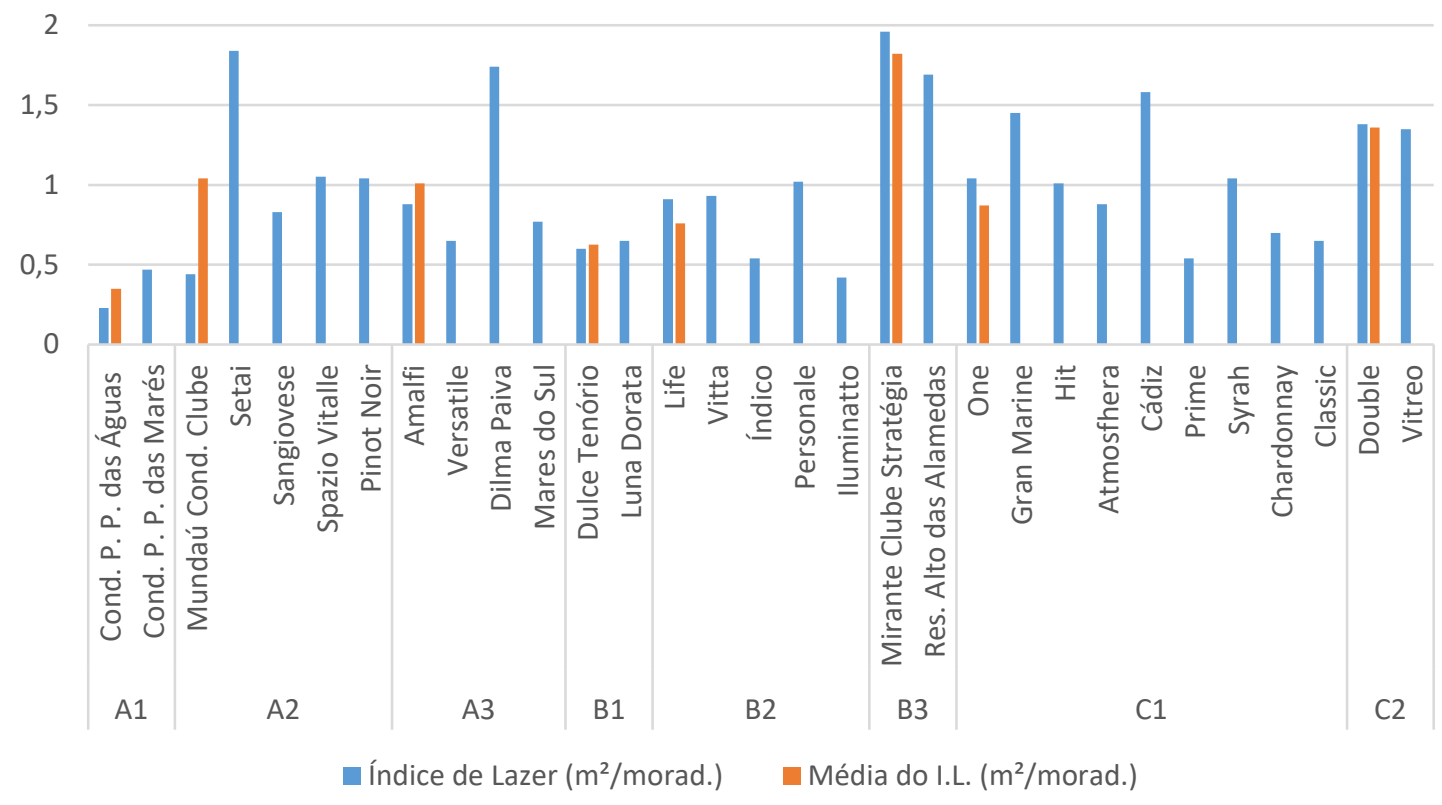

O surgimento de novos ambientes de lazer, como spa zen, garage band e espaço mulher, piscina senadinho, espaço teen, berçário, dentre outros, podem ser explicados pela economia consumista baseada no excesso, que tem como regra o surgimento dos produtos e depois a descoberta de suas aplicações, conforme constatado por Nigri (2006), no Rio de Janeiro, Nassif (2009) e Sampaio (2010), em São Paulo, Abreu (2016), em Porto Alegre e Bez (2017), em Florianópolis.

\section{Considerações finais}

Para caracterizar a configuração das áreas e dos ambientes de lazer de edifícios e condomínios verticais, visando à proposição de um índice de lazer, utilizaram-se 31 empreendimentos, lançados no período de 2010 até 2015, na cidade de Maceió, AL, os quais foram separados por três grupamentos: A, B e C, de acordo com a metragem dos apartamentos, segundo o índice de velocidade de venda (IVV) do ano de 2016.

O fato de todos os 31 componentes da amostra possuírem áreas de lazer aponta para uma tendência contemporânea para essa tipologia, atendendo aos apelos da sociedade de consumo, posto que o lazer é necessário à vida humana, e foco de interesse para os novos consumidores. Contudo, o recorte temporal considerado restringiu a amostra para uma capital em pleno crescimento urbano e para o estudo da produção contemporânea desse segmento; pesquisas mais amplas, focadas em grupos mais homogêneos poderão melhor levantar a trajetória das áreas de lazer nessa tipologia na cidade.

A análise poderia ter considerado, separadamente os condomínios e os edifícios isolados; apesar de em ambos a quantidade de ambientes de lazer ter sido relevante, sobretudo nos edifícios isolados com maior quantidade de apartamentos e para faixa de renda elevada.

Os edifícios isolados apresentaram áreas de lazer também em outros pisos como no mezanino e cobertura, não encontrados nas pesquisas similares desenvolvidas nas regiões Sul e Sudeste; já os condomínios apresentaram as áreas de lazer, principalmente, nos pavimentos térreo ou pilotis e, raramente, no subsolo.

O fato de ter sido observado, apenas em Maceió, áreas de lazer nos pavimentos mezanino e cobertura aponta para a necessidade de ampliação da pesquisa em outras capitais nordestinas, com o intuito de verificar se constitui uma expressão da arquitetura regional.

A utilização do IVV para a divisão da amostra em grupamentos pareceu mais adequada do que a divisão habitual por tipologias de apartamentos; contudo, o agrupamento de condomínios e edifícios isolados poderá ser mais bem avaliado em trabalhos futuros, posto que impactou nos índices de lazer obtidos, sobretudo nos de mais baixa renda.

Conclui-se que o índice de lazer proposto apresentou-se como um instrumento adequado para expressar a relação das áreas de lazer em função do número de moradores prováveis dos empreendimentos; contudo, 
poderá ser mais bem desenvolvido, para expressar outras variáveis, como a área total dos terrenos, proporção entre os grupos de lazer, quantidade de ambientes de lazer por grupos, etc.

\section{Referências}

ABREU, C. M. H. M. de. Lugares do brincar na infância urbana: análise do ambiente e do comportamento infantil em áreas de lazer de edifícios residenciais multifamiliares em Porto Alegre-RS. Porto Alegre, 2016. 148 f. Dissertação (Mestrado em Arquitetura) - Escola de Arquitetura, Universidade Federal do Rio Grande do Sul, Porto Alegre, 2016.

ANITELLI, F.; TRAMONTANO, M. Notas sobre o projeto de apartamentos paulistanos produzidos atualmente: propostas de uso e alterações dos ambientes e seus limites. In: SIMPÓSIO BRASILEIRO DE QUALIDADE DO PROJETO NO AMBIENTE CONSTRUÍDO, 2., Rio de Janeiro, 2011. Anais [...] Rio de Janeiro: SBQP, 2011.

BAUDRILLARD, J. A sociedade de consumo. 2. ed. Coimbra: Edições 70, 2009.

BAUMAN, Z. Confiança e medo na cidade. Rio de Janeiro: Zahar, 2009.

BAUMAN, Z. Vida para consumo: a transformação das pessoas em mercadoria. Rio de Janeiro: Zahar, 2008.

BEZ, R. M. Diretrizes para a qualificação de espaços de lazer de uso coletivo em edifícios residenciais multifamiliares em Florianópolis: um estudo fenomenológico. Florianópolis, 2017. 232 f. Tese (Doutorado em Arquitetura e Urbanismo) - Escola de Arquitetura, Universidade Federal de Santa Catarina, Florianópolis, 2017.

BROWN, P. H. How real estate developers think: design, profits, and community. Philadelphia: University of Pennsylvania Press, 2015.

CAMPBELL, C. Eu compro, logo sei que existo: as bases metafísicas do consumo moderno. In: CAMPBELL, C.; BARBOSA, L. (org.). Cultura, consumo e identidade. Rio de Janeiro: Editora FGV, 2006.

CAVALCANTE, M. C.; TOLEDO, A. M. Configuração das áreas de lazer dos edifícios verticais multifamiliares contemporâneos: estudo de caso em Maceió-AL. In: ENCONTRO NACIONAL DE TECNOLOGIA DO AMBIENTE CONSTRUÍDO, 16., São Paulo, 2016. Anais [...] São Paulo: ANTAC, 2016.

COUTINHO, M. C. C. O mercado imobiliário vende felicidade? Caracterização das áreas de lazer dos edifícios verticais multifamiliares em Maceió-AL (2010-2015). Maceió, 2016. 173 f. Dissertação (Mestrado em Dinâmicas do Espaço Habitado) - Faculdade de Arquitetura e Urbanismo, Universidade Federal de Alagoas, Maceió, 2016.

DUARTE, M. J. de C. R. Indicações para o projeto arquitetônico de edifícios multifamiliares: uma análise pós-ocupação em Natal/RN. Natal, 2007. 161 f. Dissertação (Mestrado em Conforto no Ambiente Construído; Forma Urbana e Habitação) - Escola de Engenharia, Universidade Federal do Rio Grande do Norte, Natal, 2007.

DUARTE, M. J.; ELALI, G. A. Valor de troca, valor de uso: alguns subsídios para (re)pensar o projeto de condomínios verticais. In: SIMPÓSIO BRASILEIRO DE QUALIDADE DO PROJETO NO AMBIENTE CONSTRUÍDO, 2., Rio de Janeiro, 2011. Anais [...] Rio de Janeiro: SBQP, 2011.

DUMAZEDIER, J. Sociologia empírica do lazer. 3. ed. São Paulo: Perspectiva, SESC, 2008.

EDGINTON, C. R. World leisure: enhancing the human condition. The Sport Journal, v. 12, n. 3, Summer 2009.

EDWARDS, T. Contradictions of consumption: concepts, practices and politics in consumer society. Buckingham: Open University Press, 2000.

ELLIN, N. Architecture of fear. New York: [s.n.], 1997.

FEATHERSTONE, M. Cultura do consumo e pós-modernismo. São Paulo: Studio Nobel, 1995.

FOXALL, G. Understanding consumer choice. Basingstoke: Palgrave Macmillan, 2005. 
GAVIÃO, M. M. F. Muito além do pavimento térreo: as áreas de lazer no mercado imobiliário em São Paulo. São Paulo, 2012. Dissertação (Mestrado em Arquitetura e Urbanismo) - Faculdade de arquitetura e Urbanismo, Universidade de São Paulo, São Paulo, 2012.

HAWORTH, J. T.; VEAL, A. J. (Ed.). Work and leisure. New York: Routledge, 2004.

KNEBEL, N. M. P. Questão urbana, seletividade penal e arquitetura do medo: a gentrificação do Humaitá em Porto Alegre - RS. Canoas, 2017. 239 f. Dissertação (Mestrado em Direito), Universidade La Salle, Canoas, 2017.

KOSHAR, R. (Org.). Histories of leisure. New York: Berg, 2002.

LIPOVETSKY, G. A felicidade paradoxal: ensaios sobre a sociedade de hiperconsumo. São Paulo: Companhia das Letras, 2007.

LOPES, B. L. S. As novas tipologias de edifícios residenciais verticais do litoral norte de Maceió: o caso dos condomínios clube. Maceió, 2017. 161 f. Dissertação (Mestrado em Arquitetura: Dinâmica do Espaço Habitado) - Faculdade de Arquitetura e Urbanismo, Universidade Federal de Alagoas, Maceió, 2017.

MACEIÓ. Código de urbanismo e edificações do município de Maceió. Lei Municipal n. 5.593, de 8 de fevereiro de 2007.

MARCELLINO, N. C. et al. Espaços e equipamentos de lazer em região metropolitana: o caso da RMC - Região Metropolitana de Curitiba. Curitiba: OPUS, 2007.

MARTYN, M. L. Estágios no ciclo de vida familiar e utilização de áreas de lazer em condomínios residenciais. Florianópolis, 2008. 98 f. Dissertação (Mestrado em Engenharia Civil) - Escola de Engneharia, Universidade Federal de Santa Catarina, Florianópolis, 2008.

MONETTI, E. O ponto de vista do empreendedor. In: VARGAS, H. C.; ARAÚJO, C. P. de (Org.). Arquitetura e mercado imobiliário. Barueri: Manole, 2014.

NASSIF, J. K. Áreas de lazer de edifícios residenciais de classe média: década de 1980 a 2007. São Paulo, 2009. 156 f. Dissertação (Mestrado em Arquitetura e Urbanismo) - Universidade Presbiteriana Mackenzie, São Paulo, 2009.

NIGRI, M. R. Um estudo sobre as tipologias de áreas de lazer em edifícios multifamiliares contemporâneos no Rio de Janeiro. Rio de Janeiro, 2006. 110f. Dissertação (Mestrado em Arquitetura) Escola de Arquitetura, Universidade Federal do Rio de Janeiro, Rio de Janeiro, 2006.

SAMPAIO, G. B. D. do A. Condomínios verticais residenciais na Cidade de São Paulo (2000-2008): condomínios clube. São Paulo, 2010. 312 f. Dissertação (Mestrado em Arquitetura e Urbanismo) - Escola de Engenharia, Universidade Presbiteriana Mackenzie, São Paulo, 2010.

SANTOS, F. J. de O. Análise tipológica dos edifícios multifamiliares no bairro do Farol - Maceió /AL (2000-2010). Maceió, 2016. 218 f. Dissertação (Mestrado em Arquitetura e Urbanismo) - Faculdade de Arquitetura e Urbanismo, Universidade Federal de Alagoas, Maceió, 2016.

SILVA, G. A. de S. Arquitetura do medo: cinema, espaços urbanos e tensões sociais. Recife, 2016. $186 \mathrm{f}$. Dissertação (Mestrado em Comunicação) - Universidade Federal de Pernambuco, Recife.

SINDICATO DA INDÚSTRIA. Índice de Velocidade de Vendas - Planilha IVV 2016. Disponível em: http://www.sindicatodaindustria.com.br/publicacoes/2016/02/72,81866/indice-de-velocidade-de-vendasplanilha-ivv-2016.html. Acesso em: 06 maio 2016.

VARGAS, H. C. O arquiteto e seus clientes. In: VARGAS, H. C.; ARAÚJO, C. P. de (Org.). Arquitetura e mercado imobiliário. Barueri: Manole, 2014a.

VARGAS, H. C. O fator localização revisitado. In: VARGAS, H. C.; ARAÚJO, C. P. de (Org.). Arquitetura e mercado imobiliário. Barueri: Manole, 2014b.

VARGAS, H. C. Publicidade imobiliária: o que se está vendendo? In: : VARGAS, H. C.; ARAÚJO, C. P. de (Org.). Arquitetura e mercado imobiliário. Barueri: Manole, 2014c.

VERMA, S.; LARSON, R. Examining adolescent leisure time across cultures: developmental opportunities and risks. San Francisco: Jossey-Bass, 2003.

VILLA, S. B.; ORSTEIN, S. W. Projetar apartamentos com vista à qualidade arquitetônica a partir dos resultados da avaliação pós-ocupação. Gestão \& Tecnologia de Projetos, São Paulo, v. 4, n. 2, nov. 2009. 


\section{Agradecimentos}

Agradecimento especial à Capes, pela concessão da bolsa de mestrado, a qual viabilizou a realização da presente pesquisa.

\section{Marta Cavalcante}

Faculdade de Arquitetura e Urbanismo | Universidade Federal de Alagoas | Av. Lourival Melo Mota, Tabuleiro do Martins | Maceió - AL Brasil | CEP 57072-970 | Tel.: (82) 3214-1284 | E-mail: martacristina.arquitetar@gmail.com

Alexandre Márcio Toledo

Faculdade de Arquitetura e Urbanismo | Universidade Federal de Alagoas | E-mail: prof.amtoledo@gmail.com

\section{Ambiente Construído}

Revista da Associação Nacional de Tecnologia do Ambiente Construído

Av. Osvaldo Aranha, 99 - 30 andar, Centro

Porto Alegre - RS - Brasil

CEP 90035-190

Telefone: +55 (51) 3308-4084

Fax: +55 (51) 3308-4054

www. seer. ufrgs. br/ ambienteconstruido

E-mail: ambienteconstruido@ufrgs.br

(c) (1)

This is an open-access article distributed under the terms of the Creative Commons Attribution License. 